\title{
Corticostriatal Activity in Primary Motor Cortex of the Macaque
}

\author{
Robert S. Turner and Mahlon R. DeLong \\ Department of Neurology, Emory University School of Medicine, Atlanta, Georgia 30322
}

\begin{abstract}
Although input from corticostriatal neurons (CSNs) plays a critical role in basal ganglia functions, little is known about CSN activity during behavior. We compared the properties of antidromically identified CSNs with those of antidromically identified neurons that project via the cerebral peduncle to distant targets. Both types of neurons were recorded in primary motor cortex (M1) of two monkeys as they performed a step-tracking task in which static loads opposed or assisted simple and precued movements of the elbow or wrist. Multiple lines of evidence suggested that CSNs and corticopeduncular neurons (CPNs) belong to distinct populations. No cells were activated from both striatum and peduncle. Compared with CPNs, CSNs had slow conduction velocities and low spontaneous rates, and the activity of most was unmodulated by sensory testing or within the tasks used. CSN activity resembled that described for M1-recipient striatal neurons: perimovement firing was small in magnitude, strongly
\end{abstract}

directional, and rarely showed muscle-like load effects. Contrary to a previous report, perimovement activity in most CSNs began before movement onset. CSN activity was more selective than that of CPNs: CSN sensory responses and perimovement activities were often directionally specific, CSNs were often activated exclusively by sensory stimulation, active movement, or movement preparation, and a substantial fraction of CSNs (19\%) was unresponsive to any task or manipulation. Thus, CSNs transmit signals distinct from those sent to spinal cord/brainstem. The highly selective activity of CSNs suggests that a discrete (i.e., sparse) code is used to signal cortical activation states to striatum.

Key words: primary motor cortex; basal ganglia; putamen; cerebral peduncle; arm movement; motor control; monkey; loadrelated activity; preparatory activity
The massive corticostriatal projection, which directly links cortex and the basal ganglia (BG), is the major afferent to the BG and is implicated in BG-associated disorders such as Parkinson's disease (Porter et al., 1994; Delfs et al., 1995; Calabresi et al., 1996). Despite their importance, little is known about the activity of corticostriatal neurons (CSNs) in the behaving animal (Bauswein et al., 1989; Weyand and Gafka, 1998). The idea that cortex and the BG perform dissimilar functions is based in part on the repeated observation that different aspects of a task are preferentially represented in the neuronal activities of a cortical area and the striatal area it innervates. Crutcher and Alexander (1990), for example, found that the perimovement activity of neurons in primary motor cortex (M1)-recipient striatum (dorsolateral putamen) often reflects the direction of limb movement independent of which muscles are used, whereas activity in M1 more frequently follows a pattern similar to that seen in the prime moving muscles [i.e., "muscle-like" activity; see also Kakei et al. (1999)]. The reduced importance of muscle-like activity in the putamen could result either from an intrastriatal transformation of muscle-like inputs, or from non-muscle-like information transmitted to the putamen via input pathways. Similar alternative explanations may account for other reported differences, such as a greater segregation of movement-related and preparatory activities between putamenal neurons (Alexander and Crutcher, 1990) and an increased prevalence of context-dependent activity (Kimura, 1990; Schultz et al., 1995; Ueda and Kimura, 1997; Kawagoe et al., 1998). One goal of the present study was to address these alternative explanations by studying CSN activity in the M1 of monkeys performing the same task as used by Alexander and Crutcher (1990).

\footnotetext{
Received Feb. 3, 2000; revised June 26, 2000; accepted July 5, 2000

This work was supported by National Institutes of Health Grants NS08914 (R.S.T.) and NS31937 (M.R.D.). We thank Colleen Oliver for her excellent assistance with the care and training of animals, Dr. Ikuma Hamada for his assistance in developing methods for stimulating electrode fabrication and implantation, and Dr. Michae Crutcher for his encouragement and perceptive advice throughout the course of this project. Dr. Thomas Wichman provided critical comments on this manuscript.

Correspondence should be addressed to Dr. Robert S. Turner, Department of Neurological Surgery, University of California, San Francisco, 533 Parnassus Avenue, Room U378, Box 0520, San Francisco, CA 94143-0520. E-mail: rturner@itsa.ucsf.edu. Copyright (C) 2000 Society for Neuroscience $0270-6474 / 00 / 207096-13 \$ 15.00 / 0$
}

More generally, a study of CSN activity during behavior may ascertain whether the CS system is functionally separate from other cortical efferent systems and, if so, what factors are important in its activity. Although the large distant-projecting cells of lamina $\mathrm{Vb}$ are known to collateralize to the striatum in rodents (Donoghue and Kitai, 1981; Wilson, 1987; Levesque et al., 1996), available data for primate M1 indicate that CSNs are anatomically distinct from that cell population (Jones et al., 1977). The one published study in a behaving primate showed that CSNs in M1 are also functionally distinct from pyramidal tract neurons according to spontaneous rates and the prevalence task-related activity (Bauswein et al., 1989). Responsive CSNs had activity resembling that found in the putamen: CSNs were activated exclusively by movement or sensory stimulation, and perimovement activity was relatively late in onset and seldom influenced by loads. We set out to extend those observations by comparing the activities of CSNs and corticopeduncular neurons [(CPNs) a general class of large lamina $\mathrm{V}$ neurons projecting to spinal cord and brainstem (Humphrey and Corrie, 1978)] under various conditions, with the ultimate goal of identifying what cortical information is communicated to the striatum via the activity of CSNs.

Some aspects of this work have been reported previously in preliminary form (Turner and DeLong, 1993, 1999).

\section{MATERIALS AND METHODS}

Animals, apparatus, and tasks. Two juvenile female monkeys (Macaca mullata, weighing 3.4 and $4.7 \mathrm{~kg}$ ) were used in these experiments. All aspects of animal care were in accord with the Guide for the Care and Use of Laboratory Animals (National Academy Press, 1996), and all procedures were approved by the institutional animal care and use committee.

The monkeys were trained to perform a visuomotor step-tracking task to obtain juice or food rewards. We used a behavioral paradigm similar to one used in several previous studies of cortical and BG neuronal activity (Alexander, 1987; Mitchell et al., 1987; Alexander and Crutcher, 1990). The animal sat in a primate chair and faced a computer monitor mounted $30 \mathrm{~cm}$ away at eye level. On each behavioral trial the animal was required to move a one-dimensional torquable manipulandum to align an onscreen cursor (a 5-mm-diameter white spot) with a series of targets $(1.5-\mathrm{cm}$ diameter gray circles) displayed on the monitor. A $2^{\circ}$ angular displacement of the manipulandum caused a $1 \mathrm{~cm}$ horizontal displacement of the 

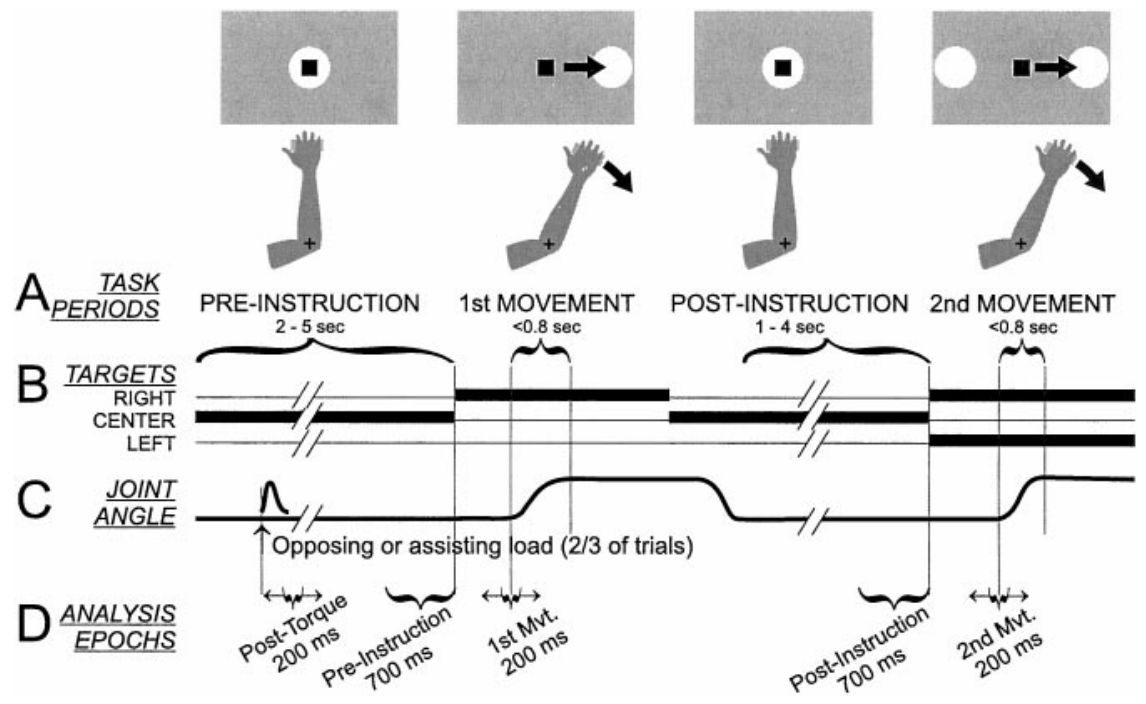

Figure 1. Schematic of the behavioral task. A, Monkeys "captured" targets (white circles) presented on a computer monitor (gray rectangle) with an on-screen cursor (black square) the horizontal position of which was controlled by flexion and extension of the wrist (for monkey L) or elbow joint (as shown for monkey B). The task required two lateral cursor movements from a central start position: the first to an unpredictable target location (right or left target, 1st MOVE$M E N T$ ) and the second guided by memory to the same target as captured previously (2nd MOVEMENT). Changes in target illumination and joint angle as a function of time are illustrated in $B$ and $C$, respectively. Static flexing or extending torques were applied to the manipulandum starting early in the PREINSTRUCTION epoch of two/three of trials. D, Five epochs were used to summarize task-related neural activity for data analysis. Two epochs (PRE- and POST-INSTRUCTION) were of fixed duration and timing relative to the first and second presentation of the lateral target, respectively. The remaining three epochs (Post-Torque, 1st Mvt. and 2nd Mvt.) were of constant duration ( $200 \mathrm{msec})$ but their timing was fixed relative to the time of a neuron's maximal change in firing for each of the three epochs. onscreen cursor. The two monkeys performed the same behavioral task, but they controlled the manipulandum using different arm movements. The first animal (monkey L) moved the manipulandum by flexing and extending the right wrist starting from a neutral angle $\left(\sim 10^{\circ}\right.$ flexed from alignment with the forearm). Monkey L's arm rested in splints, and the hand was strapped into a splint attached to the manipulandum so that the wrist joint was aligned with the axis of rotation of the manipulandum. The second animal (monkey B) moved the manipulandum by flexing and extending the elbow starting from a neutral angle $\left(\sim 80^{\circ}\right.$ into flexion from alignment with the upper arm). The animal's proximal arm rested in splints at its side, and the elbow joint was aligned with the manipulandum's axis. Proximal arm movements were used in monkey B to test the generality of the observations made in monkey $\mathrm{L}$ for a different type of arm movement.

The visuomotor step-tracking task has been described in detail previously (Alexander, 1987; Alexander and Crutcher, 1990). In brief, each trial required the monkey to perform two lateral arm movements, displacing the onscreen cursor from a center start position to "capture" a target presented to the left or right of the start position (Fig. 1). A trial began when the center target appeared and the monkey made the appropriate joint movement to align the cursor with the target. The monkey maintained this position for the duration of a preinstruction interval (random duration, $2-5 \mathrm{sec}$ ), during which the animal could not predict the location of the upcoming lateral target. The target then shifted to the left or right, and the monkey moved the cursor to capture the lateral target (Fig. 1 $\mathrm{A}$, 1st $M O V E M E N T)$. After a target hold interval $(0.75-1.5 \mathrm{sec})$, the center target reappeared, and the monkey moved to capture it, thereby beginning the postinstruction interval ( $1-4 \mathrm{sec})$. During this interval, the monkey was required to remember the direction of the previous movement so as to perform a correct second movement. At the end of the postinstruction interval, lateral targets appeared to both the left and right of the center target, and the monkey recaptured the same target as captured in the first lateral movement (Fig. 1 $A$, 2nd MOVEMENT). After another target hold interval $(0.75-1.5 \mathrm{sec})$, the monkey received a drop of juice or food.

On two-thirds of the trials (randomly selected), a constant flexing or extending torque load $(0.1 \mathrm{Nm})$ was applied to the manipulandum beginning 1-2 sec after initial capture of the center target and lasting until reward delivery (Fig. $1 C$ ). The loaded trials served three purposes: (1) to evaluate short-latency neural responses to torque perturbations, (2) to evaluate neural sensitivity to static torque during the preinstruction period, and (3) to dissociate the direction of active movement from the pattern of muscle activity used to perform the movement. When loading direction and the direction of movement were opposed, movement was performed by increasing activity in the already active agonist muscles, whereas when loading direction and movement direction were the same, movement was performed by reducing tonic postural activity in the antagonist muscles [see Alexander and Crutcher (1990) for details].

Surgery. After training, each monkey was surgically prepared for recording using aseptic surgery under isoflurane inhalation anesthesia. A cylindrical stainless steel chamber [18 mm inner diameter (ID)] was implanted with stereotaxic guidance over a burr hole allowing access to the armrelated regions of the right $\mathrm{M} 1$ and the posterior putamen [centered on Horsley-Clark (HC) anterior (Ant) 10, lateral (Lat) 20, depth (Z) 20 (Winters et al., 1969)]. The chamber was oriented parallel to the coronal plane and at an angle of $\sim 35^{\circ}$ so that electrode penetrations would be orthogonal to the cortical surface. The chamber was fixed to the skull with bone screws and dental acrylic. Bolts were embedded in the acrylic to allow fixation of the head during recording sessions.

Placement of stimulating electrodes. Several days after the monkey recovered from surgery, sites for implantation of stimulating electrodes were identified using standard electrophysiological mapping techniques. Special care was taken to identify appropriate implantation sites in the putamen because of the topographic yet patchy nature of the corticostriatal innervation (Flaherty and Graybiel, 1991). The goal was to identify sites in the putamen that receive dense innervation from the arm area of M1 (Liles, 1975). Mapping was performed with glass-coated PtIr microelectrodes mounted in a hydraulic microdrive (Narishige International, Tokyo, Japan) to explore the portion of the putamen accessible through the lateral aspect of the recording chamber. Arm-related areas of the putamen were identified by sensorimotor examination of striatal activity and microstimulation effects $[<60 \mu \mathrm{A}, 40$ biphasic constant current pulses at $300 \mathrm{~Hz}$ (Alexander and DeLong, 1985)]. Mapping results for the two animals are summarized in Figure 2. The arm-related fiber tract in the prepontine cerebral peduncle [ventral to the substantia nigra, approximate HC location Ant 9, Lat 8, Z -1 (Winters et al., 1969)] was located using similar techniques.

Custom-built "floating" stimulating electrodes were implanted at identified arm-related sites in putamen and the peduncle (Fig. 2, gray circles). Each electrode assembly consisted of one to three Teflon-coated PtIr microwires (each $50 \mu \mathrm{m}$ diameter) (A-M Systems, Carlsborg, WA) fixed with cyanoacrylate glue (Loctite 420, Loctite Corp., Rocky Hill, CT) inside a short $(\sim 5 \mathrm{~mm})$ length of stainless steel cannula [30 ga outer diameter, adapted from a design of Jaeger et al. (1990)]. The cut ends of the microwires extended below the cannula tip by $>1 \mathrm{~mm}$ at depths staggered by $0.5 \mathrm{~mm}$. Electrode assemblies were implanted transdurally through the chronic recording chamber using a guide tube (28 ga ID) and stylus (0.2 mm diameter; A-M Systems) mounted in the microdrive. The guide tube contained the electrode assembly and the stylus above it. The tip of the stylus rested on top of the electrode assembly's cannula, and the proximal ends of the microwires passed alongside the stylus to exit the guide tube at its top. The dura was first penetrated by the guide tube with the electrode withdrawn inside. The electrode assembly was then pushed out of the guide tube and into the brain using the microdrive-mounted stylus. The location of the electrode tip relative to the map (previous paragraph and Fig. 2) was monitored using multiunit activity and the effects of stimulation. On reaching the target location for implantation, the guide tube and then stylus were withdrawn, and the electrode assembly was left floating in the brain with only the proximal ends of the microwires exiting the dura. The proximal ends were led through a port in the side of the recording chamber (which was subsequently sealed with cyanoacrylate glue) and soldered to a head-mounted connector. After implantation, stimulation through the electrodes invariably evoked arm movements similar to those observed at the target sites during microelectrode mapping. In both animals, three such electrodes were implanted in the posterior putamen between the planes of HC Ant 8 and 14, and one electrode containing two microwires was implanted in the arm-responsive portion of the prepontine peduncle (Fig. 2). Each electrode was checked periodically throughout the course of the experiment to ensure that a train of stimuli evoked a consistent motor effect. Histological reconstruction confirmed that the striatal and peduncle electrodes were at sites shown by anatomical studies to receive the bulk of M1 CS and CP projections, respectively (Brodal, 1978; Flaherty and Graybiel, 1991; Takada et al., 1998).

Data acquisition. Areas of M1 related to the primary joint used in the task were identified using microstimulation and sensorimotor mapping. A cortical region was determined to be "task-related" if neurons responded to active and/or passive movement of the appropriate joint and microstimulation at low currents evoked joint movement or muscle contraction $(<40$ microamps, 10 biphasic pulses at $300 \mathrm{~Hz})$.

Microelectrode penetrations were performed throughout the taskrelated cortical areas while we searched for neurons activated antidromically from the putamen or peduncle stimulating electrodes. As the elec- 


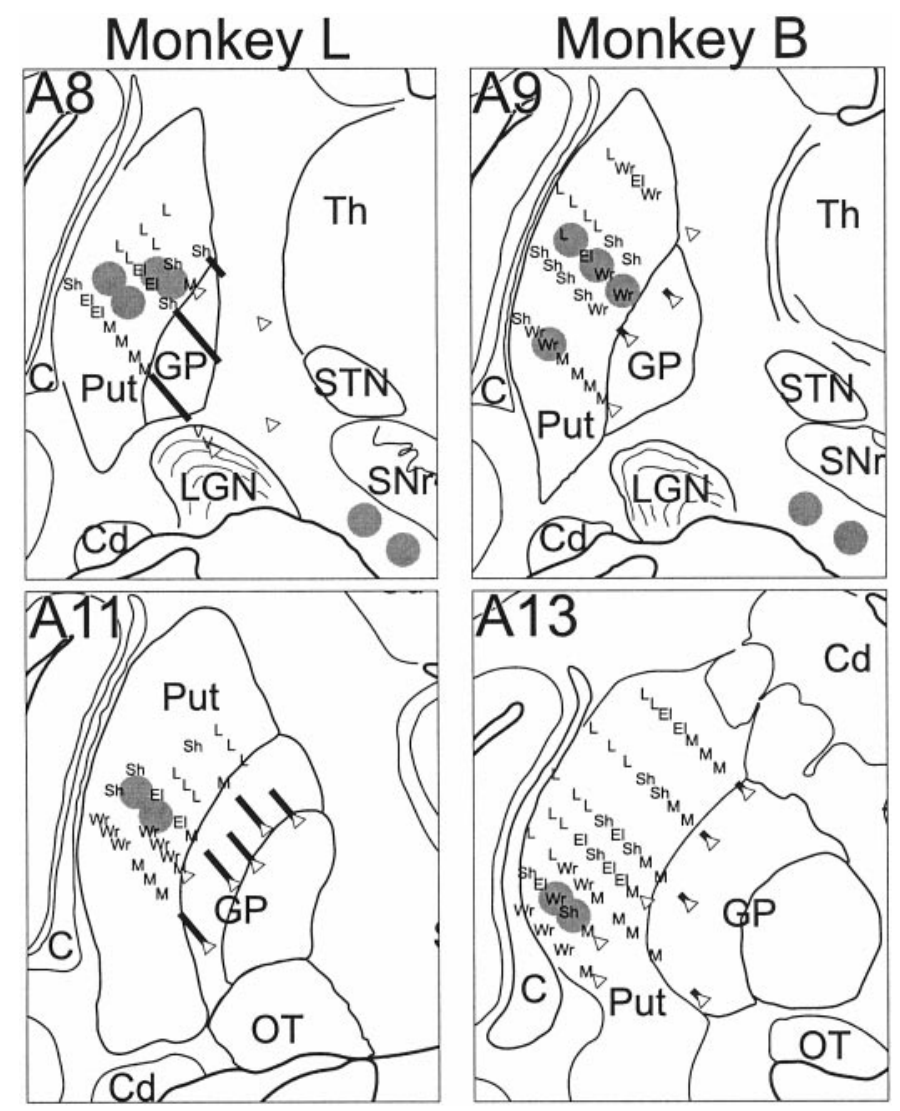

Figure 2. Locations of chronic indwelling stimulating electrodes relative to microelectrode mapping of putamen and cerebral peduncle. The approximate location of each stimulating lead is denoted by a gray circle. Microstimulation results and somatosensory response properties of neurons encountered along recording tracks are summarized as follows: $E l$, elbow; $L$, leg; $M$, mouth; Sh, shoulder; $V$, visual; $W r$, wrist. Open triangle indicates the point of deepest penetration of an electrode track. Thick diagonal line indicates the portion of an electrode track where high-frequency activity characteristic of the globus pallidus was encountered. The boundaries of surrounding structures are shown for orientation: $C$, claustrum; $C d$, caudate; GP, globus pallidus; $O T$, optic tract; Put, putamen; $S N r$, substantia nigra reticulata; $S T N$, subthalamic nucleus; $T h$, thalamus. Maps were reconstructed from histological sections and microelectrode recording tracks. Data from $2 \mathrm{~mm}$ in the anterior/posterior dimension are collapsed onto one coronal section.

trode was advanced, stimuli were delivered sequentially to each putamen and peduncle stimulating site (single $-/+$ biphasic constant current pulses of $700 \mu \mathrm{A}$, each phase $0.2 \mathrm{msec}$ duration separated by $0.1 \mathrm{msec},>1.5 \mathrm{sec}$ between successive biphasic shocks). Various combinations of electrode pairs and polarities were used both to increase the chances of activating a cell and to minimize the size of the shock artifact. The standard tests for antidromic identification were used: a constant antidromic latency $(<0.2$ msec jitter), reliable following of a high-frequency train of stimuli (three or four shocks at $200 \mathrm{~Hz}$ ), and collision of antidromic spikes with spontaneously occurring spikes (Fuller and Schlag, 1976) (see also Fig. 4). Antidromic latency was measured as the time from stimulation onset to the first inflection in the waveform of the antidromic spike. For most antidromically activated cells, the threshold current for activation was determined $(\sim 50 \%$ probability of evoking a spike), and tests for antidromic identification and latency were typically performed at two times threshold or $700 \mu \mathrm{A}$, whichever was smaller. The tests were performed using a custom PC-based data acquisition system that digitized ( $20 \mathrm{kHz}$ sampling rate), displayed, and stored peristimulus sweeps of the amplified analog unit signal.

Neuronal activity was monitored while the animal performed the steptracking task. The action potentials of single neurons were detected using a template-based spike sorting system that allowed the simultaneous discrimination of spikes from multiple neurons (Alpha Omega Engineering, Nazareth, Israel). The times of discriminated spikes were saved to disk with millisecond accuracy. For neurons that generated few spontaneous spikes, the isolation of action potentials was tested during intertrial intervals using the spikes evoked by antidromic activation. Analog data were digitized at either $200 \mathrm{~Hz}$ (monkey L) or $500 \mathrm{~Hz}$ (monkey B). The six trial types (two lateral targets $\times$ three loading conditions) were presented in random order until 10 repetitions of each trial type were collected.
After task completion, we monitored the activity of a neuron during a sensorimotor examination (Alexander and DeLong, 1985; Turner and Anderson, 1997). The exam included manually imposed joint rotations, muscle palpations, tendon taps, and cutaneous stimulation of the animal's arms, legs, back, and neck. Whether a neuronal response was selective for specific stimuli (e.g., joint directions and/or postures) was determined qualitatively by imposing a wide variety of stimuli and monitoring the activity of the neuron. Neural activity was also monitored while the animal performed reaching movements to retrieve raisins from a Klüver board and place them in its mouth. After the examination, microstimulation was performed at the site of unit recording $(<40 \mu \mathrm{A}, 10$ biphasic pulses at $300 \mathrm{~Hz})$.

In monkey L, EMG activity was also recorded during task performance in separate sessions after the last neural recordings. The following muscles were studied: flexor carpi ulnaris, flexor carpi radialis, flexor digitorum prof undus, extensor digitorum communis, extensor digitorum VI and V, extensor carpi radialis and ulnaris, palmaris longus, abductor pollicis longus, biceps longus, brachioradialis, triceps lateralis, anterior deltoid, and latissimus dorsi.

After the last recording session, each monkey was given a lethal dose of sodium pentobarbital and was perfused transcardially with saline followed by $10 \%$ Formalin in phosphate buffer and then sucrose. The brains were blocked in place in the coronal plane, removed, cryoprotected with sucrose, cut into $50 \mu \mathrm{m}$ sections, and stained with cresyl violet. The locations of stimulating and recording sites were reconstructed using gliosis left by electrode penetrations, the tracks left by pins inserted immediately before perfusion, and the site coordinates relative to the center of the recording chamber.

Data analysis. For each behavioral trial, spike density functions (SDFs) were constructed as the sum of Gaussian functions (unit area, $10 \mathrm{msec}$ variance) centered on the times of each discriminated action potential within a trial [for method, see Szucs (1998)]. A neuron's task-related activity was summarized for each trial by extracting mean rates for epoch associated with five behavioral events (Fig. 1D): (1) post-torque, (2) preinstruction hold period, (3) first movement, (4) postinstruction hold period, and (5) second movement. For the preinstruction and postinstruction periods, single trial SDFs were averaged over the $700 \mathrm{msec}$ epoch that immediately preceded presentation of the first and second lateral targets. For the other three events, SDFs were sampled at a time close to each event at which the firing rate of the cell deviated maximally from baseline. This approach was used because more traditional approaches (i.e., behaviorally defined epochs) failed to detect many of the consistent but shortlasting firing changes observed in CSNs. First, for each event, the largest deviation in firing (increase or decrease from baseline) was found for a predefined peri-event epoch (post-torque: $250 \mathrm{msec}$ immediately after torque onset, first and second movement: $300 \mathrm{msec}$ before to $300 \mathrm{msec}$ after movement onset). Mean SDFs (averaged across trials) for each of the six trial types were searched independently, and the point of the largest deviation across all trial types was taken as the time of the epoch's maximal firing rate deviation. Finally, single trial mean firing rates were extracted for a short epoch $(200 \mathrm{msec})$ (Fig. $1 D$, brackets with arrows) centered on the time of the maximal deviation.

Movement-related activity and the influences of movement direction and load were detected using a three-way ANOVA. The ANOVA compared the mean firing rate of a cell around the time of first movement with activity during the preinstruction period. The first factor of the ANOVA, behavioral epoch, was treated as a repeated measure (two levels: preinstruction and first movement), and the other two factors coded target direction (flexion and extension) and torque load (flexor, no-load, and extensor). A neuron was judged to have significant perimovement activity if the results of the ANOVA exceeded the threshold for statistical significance $(p<0.001)$ either in the main effect of epoch or in any of the interaction terms that included epoch as a factor (i.e., epoch $\times$ direction, epoch $\times$ load, or epoch $\times$ direction $\times$ load). Results of the same ANOVA were used to evaluate the influences on a neuron's perimovement activity of movement direction, torque load, and the interactions of direction and load. As in other single-unit studies using multifactor ANOVAs (Alexander and Crutcher, 1990; Clower and Alexander, 1998), the predefined criterion for statistical significance $(\alpha)$ was set at $p<0.001$.

Preparatory activity was detected with a second three-way repeated measures ANOVA. In this case, the preinstruction and postinstruction epochs were compared as the first (repeated) factor. The remaining two factors, as before, coded target direction and torque load. A neuron was judged to have preparatory activity if the ANOVA yielded a significant main effect of epoch $(p<0.001)$ or significant interactions between epoch and direction and/or load. Responses to the onset of torque loads were assessed with a one-way ANOVA comparing firing rates during the posttorque epoch for the three load conditions (flexor, extensor, and no-load) Finally, the influence of loads on a neuron's tonic firing was assessed with a two-way ANOVA that compared firing rates during the preinstruction epoch for different loads and different (upcoming) target directions. As one might expect, target direction never had a significant influence on a cell's firing during the preinstruction period, so the ANOVA reduced to a one-way ANOVA with three torque levels (flexor, extensor, and no-load).

The onset times of changes in activity after torque perturbations and around movement onset were determined from peri-event SDFs (means across trials of one condition). Onsets were defined as the time at which the SDF first deviated from the preresponse control level by 2.5 SDs for $>20$ 


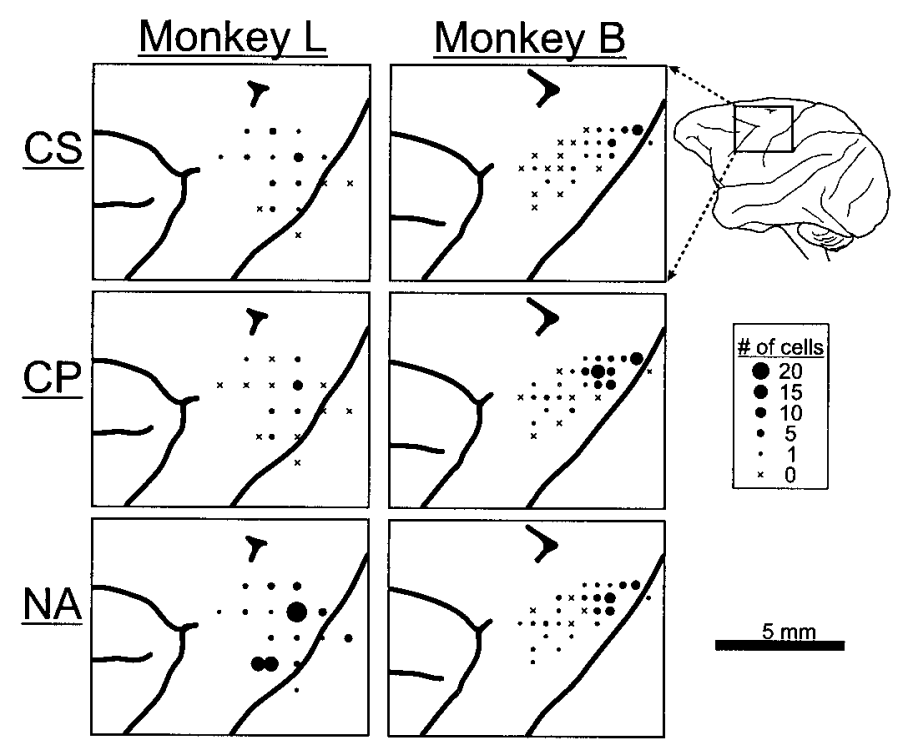

Figure 3. Surface map of electrode penetrations in M1. Separate maps are shown for each of three cell types ( $C S$, corticostriatal; $C P$, corticopeduncular; $N A$, not activated) in the two monkeys. Circle diameters indicate the number of cells of each type that were sampled at each location. The maps were derived from photographs of the cortical surface taken after perfusion, histological sections, and the chamber locations for recording tracks.

msec. The latency of torque responses was determined separately for each loading condition that produced a significant torque response (as determined by ANOVA; see above). The control mean and SD were taken from the $500 \mathrm{msec}$ period immediately preceding torque onset. Likewise, the latencies of perimovement activity were determined for all target directions and loading conditions producing significant perimovement activity during the first movement epoch (as determined by ANOVA). Control values were from a $500 \mathrm{msec}$ period immediately preceding presentation of the first lateral target. On rare occasions when the experimenter disagreed with the algorithm's estimate, onset times were corrected manually. For comparisons between populations, the earliest onset across conditions was used as a cell's latency.

An index of directional modulation (IDM) was used to compare the incidence of different patterns of directional modulation in torque responses and perimovement activity. The IDM was calculated according to the following equation: IDM $=100 \times|F-E| /|M M|$. The IDM reflected the absolute magnitude of the directional modulation in activity (the difference in firing rates for flexion, $F$, and extension, $E$, directions) as a percentage of a cell's absolute maximal perimovement change from spontaneous rate $(M M)$. An IDM of $0 \%$ would indicate that a cell's activity was not influenced by direction (of torque or active movement) and therefore was exactly bidirectional, whereas a directional modulation of $200 \%$ would indicate that the activity was perfectly reciprocal with changes of equal magnitude but opposite sign for opposing directions of movement. For categorical analysis, "unidirectional" activity was arbitrarily defined as an IDM within the $80-120 \%$ range, which would indicate that the change in firing for the preferred direction (the direction associated with a maximal change in firing) was $\geq 5$ times the magnitude of that for the opposing direction.

\section{RESULTS}

Electrode penetrations were made at 43 locations in the arm territory of the left M1 of two monkeys (Fig. 3). For more anterior electrode penetrations, neurons were included only if they were at, or posterior to, sites where microstimulation evoked arm movements at low threshold (i.e., $<30 \mu \mathrm{A}, 10$ pulses at $300 \mathrm{~Hz}$ ), thereby ensuring that neurons from the caudal premotor cortex were excluded (Weinrich and Wise, 1982). Neurons were included if they were encountered in a task-related cortical region and were either responsive to antidromic simulation or within $0.5 \mathrm{~mm}$ of an antidromically activated neuron.

Of the 374 neurons studied during task performance, 75 were activated antidromically from the putamen (CSNs; 35 in monkey L and 40 in monkey $\mathrm{B}$ ), and 115 were activated from peduncle stimulation (CPNs; 23 in monkey L and 92 in monkey B). Although

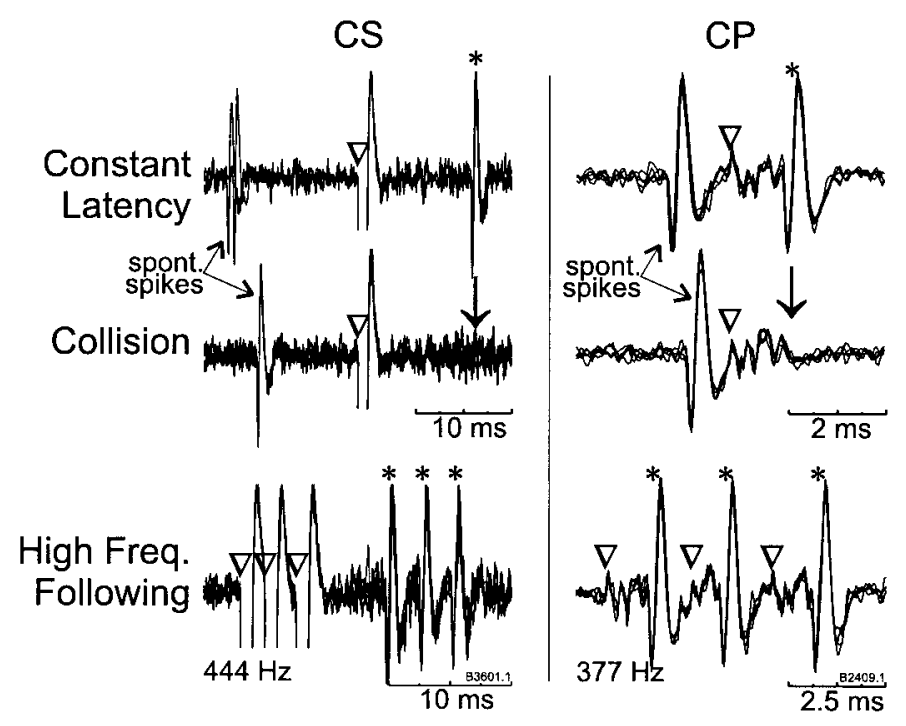

Figure 4. Antidromic activation of M1 neurons from stimulating electrodes in the striatum $(C S)$ and peduncle $(C P)$. Antidromically elicited action potentials $\left({ }^{*}\right)$ occurred at a constant latency after stimulation $(\nabla)$. Antidromic spikes collided $(\downarrow)$ with spontaneous spikes when stimulation was delivered after a spontaneous spike at any delay shorter than the cell's antidromic latency plus the refractory period. Finally, a high-frequency $(>300 \mathrm{~Hz})$ train of three stimuli $(\nabla \nabla \nabla)$ reliably evoked three antidromic spikes $(* * *)$. Because of an idiosyncrasy of the stimulus generator, the first and second interstimulus intervals in these trains are not exactly equal. The nominal frequency of the stimulation train is noted below each example of frequency following. Four to six repetitions are overlaid for each of the traces shown.

neurons were often activated from several stimulating electrodes within the putamen or peduncle, none were activated from both the putamen and peduncle. Figure 4 shows examples of impulse collision and high-frequency following for a CSN (left) and a CPN (right). The action potentials of CSNs were typically of small amplitude and discriminable over a small range of electrode positions $(<100 \mu \mathrm{m})$. On many occasions, action potentials were observed at a constant latency after putamen stimulation, but they were either too small or too sensitive to small shifts in electrode position for reliable spike sorting.

The remainder of the neurons $(n=184)$ were not activated antidromically (NA) but were recorded either at the same time as CS or CP recordings $(n=58)$ or were encountered within $0.5 \mathrm{~mm}$ above or below an antidromically activated neuron along the same track. Not all neurons remained well isolated, so the number of trials per condition did not always amount to 10 , and the numbers of cells in a category varied for different comparisons.

\section{Conduction velocity and spontaneous activity}

In addition to the observation that no neurons were activated antidromically from both the putamen and the peduncle, other observations reinforced the view that CSNs and CPNs belong to distinct populations. The axonal conduction velocities of CSNs were considerably slower than those of CPNs (Fig. $5 A$ ). The antidromic spikes of CSNs had remarkably long latencies (range: 2.6-14.4 msec) compared with those of CPNs (range: 0.75-3.6 $\mathrm{msec}$ ). Taking into account the estimated distances from stimulating sites in putamen and peduncle $(20-25$ and $31 \mathrm{~mm}$, respectively), there was virtually no overlap between the conduction velocity distributions for CSNs and CPNs (Fig. 5A) ( $p<0.0001$, Komolgorov-Smirnov two-sample test).

The spontaneous firing rates of CSNs were markedly lower than those of most CPNs (Fig. 5B). Spontaneous rates were measured during the preinstruction epoch of nonloaded trials. During this epoch the monkey maintained a central cursor position while waiting for a lateral target to appear. CSNs seldom fired $>5$ spikes/sec (median rate 1.4 spikes/sec, range: 0-11 spikes/sec), 

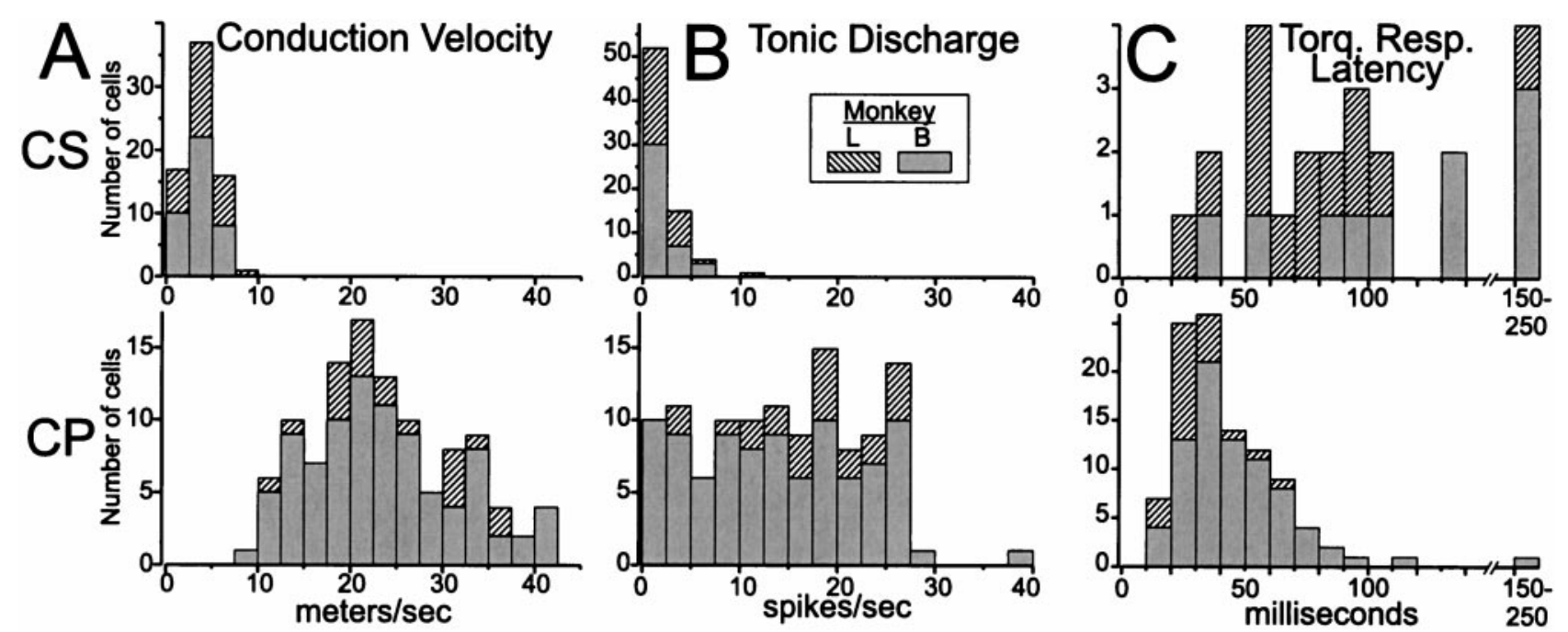

Figure 5. Distributions of basic properties for CSNs and CPNs. CSNs had slower conduction velocities than CPNs $(A)$, lower spontaneous firing rates $(B)$, and longer latency somatosensory responses $(C)$ for the few CSNs that did respond to torque perturbations. (Note different ordinate scales for CS and $\mathrm{CP}$ distributions in $C$.) These differences between CSNs and CPNs were all highly significant and were consistent for the two animals studied.

whereas most CPNs exceeded 10 spikes/sec (median rate 14.8 spikes/sec, range: 0.2-38 spikes/sec; Komolgorov-Smirnov twosample test, $p<0.0001)$.

\section{Sensory responses}

CSNs were also notable for their relative unresponsiveness to somatosensory stimulation and for the highly selective nature of the responses that were found. Somatosensory responsiveness was assessed in two independent ways: (1) qualitatively, by monitoring a neuron's firing during the sensorimotor examination, and (2) quantitatively, by measuring the short latency effects of load applications to the joint. Qualitatively, CPNs were more likely to respond to somatosensory exam $(80 / 102$ neurons, $78 \%)$ than CSNs $(22 / 63$ neurons, $\left.35 \% ; \chi^{2}=31.2, p<0.00001\right)$. The relative paucity of sensory responses in CSNs could not be accounted for by their low tonic firing rates. Other neuronal types with low spontaneous rates (i.e., subpopulations of CPNs and NA neurons with tonic rates $<7.5$ spikes/sec) responded far more frequently than CSNs to somatosensory stimulation (83 and $71 \%$ of slowly firing CPNs and NA neurons, respectively). Regardless of neuronal type, somatosensory responses were nearly always proprioceptive, as judged by their selectivity for joint rotations or, on occasion, deep probing of muscles and/or tendon taps. In monkey L, in which the wrist- and hand-related areas of M1 were explored, a small number of CSNs and CPNs (six in all) responded to light touch with distinct receptive fields on the glabrous skin of the hand. Within CS and CP populations, sensory responsive and unresponsive neurons had similar spontaneous rates and axonal conduction velocities.

For the CSNs that did respond during the sensory exam, a common feature was selectivity for specific conditions. Some neurons exhibited a discrete sensitivity to experimenter-imposed rotation of one joint in one direction. Others showed even greater selectivity by responding to rotation of one joint in one direction, but only when the arm was held in a certain posture. For example, one CSN responded only during imposed extensions of the right elbow when the animal's arm was held with the shoulder abducted and extended in the transverse plane. The neuron did not fire during elbow extensions when the shoulder was flexed in the transverse plane, nor was its activity modulated during task performance or sensorimotor examination. $\mathrm{CP}$ and $\mathrm{NA}$ neurons within $0.5 \mathrm{~mm}$ of this $\mathrm{CSN}$ responded to passive and active elbow rotations regardless of arm position. A similar degree of selectivity was found in 8 of the 22 sensory exam-responsive CSNs $(36 \%)$ but never in CPNs $\left(0 / 80 ; \chi^{2}=26.6, p<0.00001\right)$. All sensory-selective CSNs were driven by a very narrow range of stimuli often depending on a combination of factors: the location and direction of the stimulation (e.g., radial deviation of the wrist), the position of other joints of the arm, and sometimes postural tone (i.e., whether there was discernable resistance to passive movement of the joint). Given the practical difficulty of exploring all permutations of the multiple factors, it is probable that some CSNs were classified as unresponsive merely because a relatively restricted range of stimuli was used.

A quantitative analysis of short latency torque responses further supported the view that CSNs were difficult to drive with somatosensory stimulation and that the sensory responses of CSNs were more selective than those of other neuronal populations. Cortical activity that follows a torque perturbation at short latency $(<60$ $\mathrm{msec}$ ) is related to somatosensory inflow, whereas activity related to compensatory movement follows later (Evarts, 1973). Torque responses $(p<0.001$, ANOVA) were observed at short latency $(<60 \mathrm{msec})$ in a small number of CSNs $(7 / 67,10 \%)$ (Fig. $5 C)$, far fewer than the $75 \%$ of CPNs with short latency responses $(84 / 112$; $\left.\chi^{2}=69.9, p<0.00001\right)$. The paucity of sensory responses among CSNs was not attributable to their low spontaneous rates, because short latency torque responses were common among other neuronal types that had comparable spontaneous rates (among cells firing $<7.5$ spikes/sec, $72 \%$ of CPNs and $75 \%$ of NA neurons responded at latencies $<60 \mathrm{msec}$ ). Within $\mathrm{CS}$ and $\mathrm{CP}$ populations, there was a trend for cells with lower spontaneous rates to respond at longer latencies (correlation coefficients $=-0.4$ and -0.18 for $\mathrm{CS}$ and CP populations, respectively; $p=0.057$ and 0.04 ), but this effect could not account for the absence of torque responses in the majority of CSNs.

The short latency torque responses of CSNs were directionally selective more frequently than those of other neurons. The seven short latency responses found for CSNs were either present for only one torque direction (e.g., for extending loads as in Fig. $6 \mathrm{~A}$, right panel) $(n=3)$ or were reciprocal with an increase in firing for one direction and a decrease for the opposite direction (Fig. 6C) $(n=4)$. A smaller proportion of CPNs had directionally selective responses [16\% unidirectional (14/84 cells) and $43 \%$ reciprocal $(36 / 84)$ (Fig. $\left.6 D), \chi^{2}=4.6, p<0.03\right]$. Torque responses not selective for direction (i.e., "bidirectional" responses) accounted for $41 \%$ of the CPN responses (34/84) (Fig. 6B) but were never observed in CSNs.

\section{Perimovement activity}

Modulation of activity around the time of movement was much more common among CPNs than CSNs. Figure 7 illustrates a dramatic example in which we simultaneously monitored the activity of a CPN and a CSN. The CSN had a low spontaneous rate that 

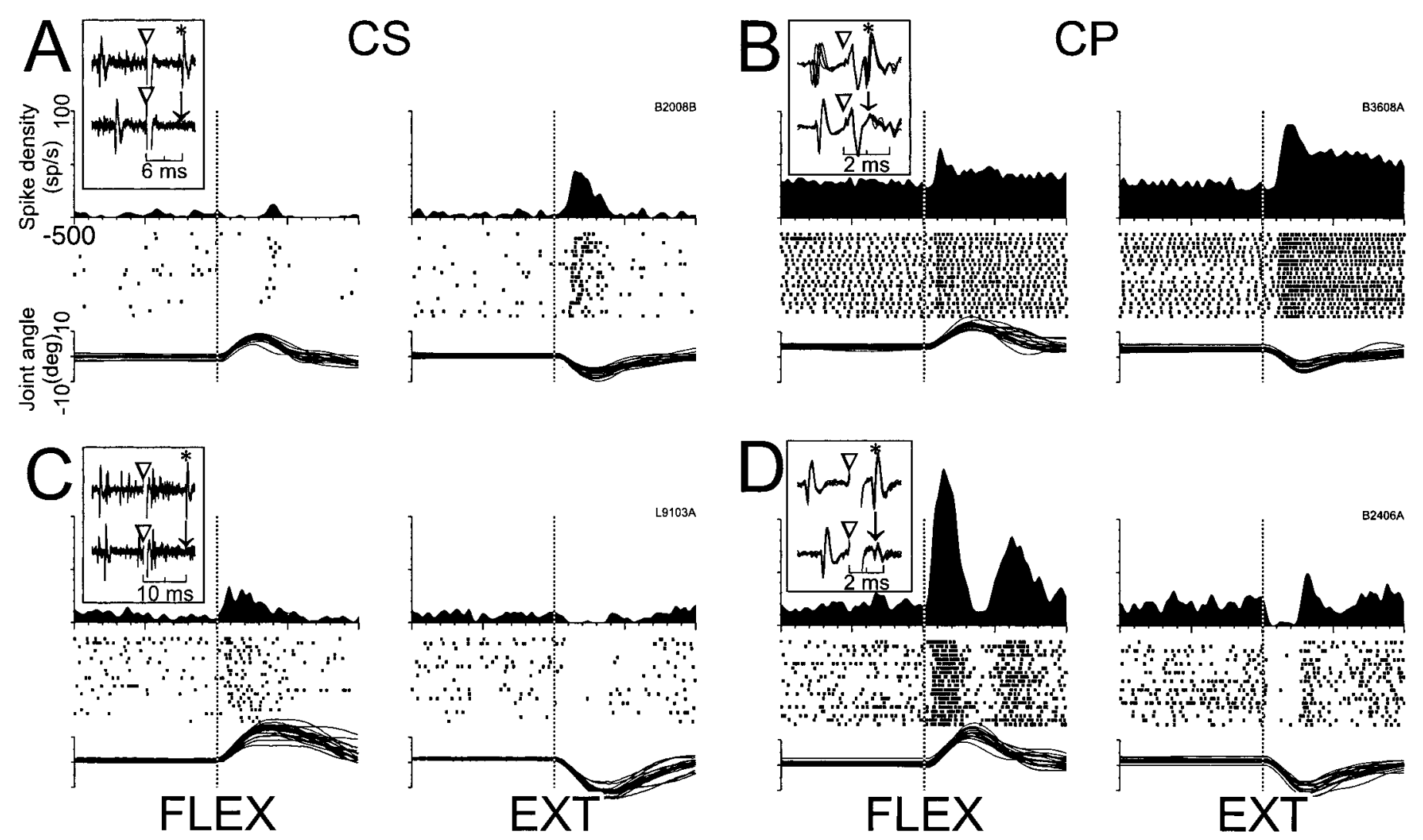

Figure 6. Representative short latency responses to torque perturbations for CSNs and CPNs. The torque responses of CSNs tended to be small in magnitude and either unidirectional $(A)$ or reciprocal $(C)$ in nature, whereas the responses of CPNs were most commonly bidirectional $(B)$ or reciprocal $(D)$. Mean SDFs, rasters, and overlaid traces of single trial joint angle are aligned on the onset of flexing and extending torques (vertical dotted lines in left and right subpanels, respectively). Inset figures in each panel follow the conventions of Figure 4 to illustrate antidromic activation and collision tests for the neuron that has its torque response shown.
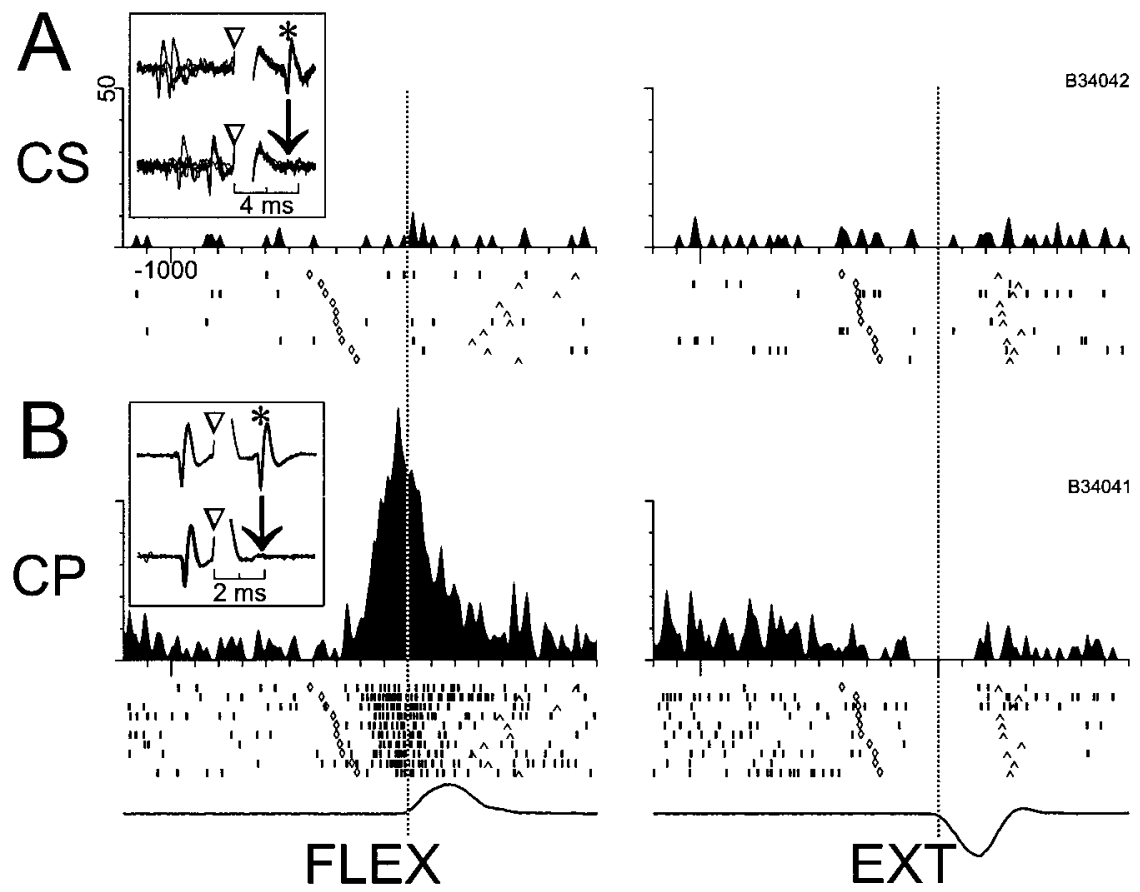

Figure 7. Simultaneously recorded activity of CS and $\mathrm{CP}$ neurons around the time of movement. $A, \mathrm{CSNs}$, as shown for this example, frequently had a low spontaneous rate that was not modulated around the time of movement (left and right subpanels show flexion and extensions movements, respectively). $B$, CPNs, in contrast, nearly always had significant perimovement activity. For this CPN, a marked increase in firing began $\sim 200 \mathrm{msec}$ before flexion movements (left), and a small decrease in activity was present for extensions (right). Mean SDFs (top), raster diagrams (with trials sorted according to the trigger-to-movement interval, middle), and mean angular velocity (bottom) are aligned on the time of movement onset (vertical dotted lines). In the raster diagrams, symbols along one row indicate the times of unit firing $(\mid)$, target appearance $(\diamond)$, and movement termination $(\wedge)$ for a single trial. Inset figures illustrate the antidromic activation and collision tests for the two neurons. Action potentials from the CPN are not seen in the inset in $A$ nor are CSN action potentials seen in the $B$ inset, because of the low spontaneous rates of both neurons.

was unmodulated around the time of movement (Fig. 7A), whereas the $\mathrm{CPN}$ had a large increase in firing preceding flexion movements and a reciprocal reduction preceding extensions (Fig. 7A). Perimovement changes in activity $(p<0.001$, three-way ANOVA) were found in far more CPNs $(96 \%, 110 / 115)$ than CSNs $(49 \%$, $\left.35 / 72 ; \chi^{2}=56.3, p<0.000001\right)$. The subpopulations of CPNs and
NA neurons with low spontaneous rates $(<7.5$ spikes/sec) also had high incidences of movement-related activity (96 and 88\%, respectively), thereby indicating that the relative paucity of perimovement activity in CSNs could not be attributed solely to their low spontaneous rates. The perimovement modulations found in CSNs tended to be of smaller absolute magnitude than those of CPNs 

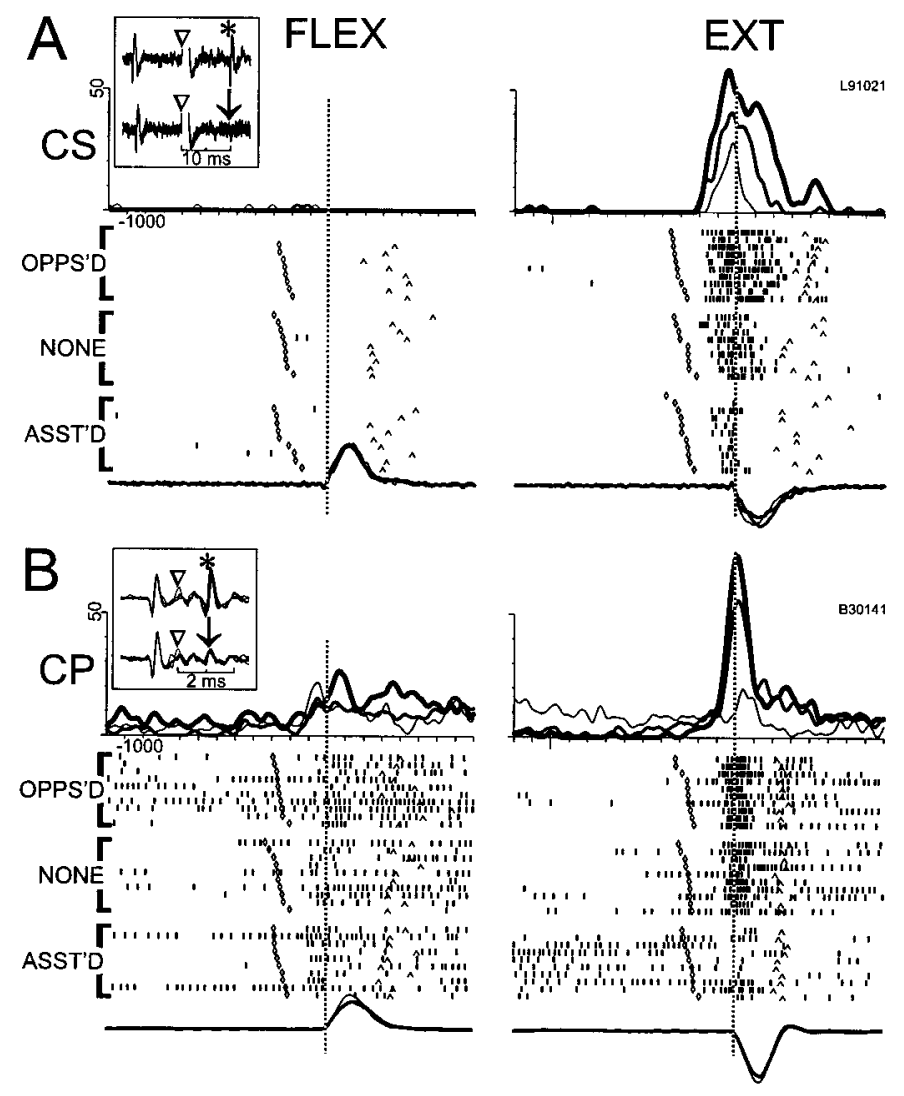

Figure 8. Representative examples of "muscle-like" patterns of perimovement activity in $\mathrm{CS}$ and $\mathrm{CP}$ neurons ( $A$ and $B$, respectively). The perimovement firing of both cells was directional, with large increases preceding extension movements (right subpanel) and little or no change for flexions (a small increase in $B$ and no change in $A$ ). The activity was categorized as "muscle-like" because the increase was larger when torque loads opposed extension (thick lines in SDF and top raster diagram, OPPS'D) and smaller when loads assisted extension (thin lines in SDF and bottom raster diagram, $A S S T$ 'D). Movement kinematics were similar across loading conditions as can be seen by comparing the mean angular velocities for the three loading conditions (overlaid traces below raster diagrams). Separate mean SDFs and raster diagrams are shown for the three loading conditions. Otherwise, the figure follows the conventions outlined for Figure 7.

(Fig. 10A) (means $=17.7$ spikes/sec vs $31.3 \mathrm{spikes} / \mathrm{sec}$ for CSNs vs CPNs; $t=5.03$, df $=143, p<0.00001)$.

A handful of the CSNs not activated by movement within the formal task $(17 \%, 6 / 35$; two not tested) became active when the animal engaged in a motor behavior with the arm free from the manipulandum. Each neuron was activated by a different behavior, but most cells fired during one or another discrete component of the Klüver board task (e.g., during finger extension into the Klüver board slot, or when bringing the hand to the mouth after retrieving a raisin). These responses were judged to be movement-related because they were consistently present across several repetitions of the activating behavior, but they were absent when the arm was moved passively through motions that imitated the activating behavior.

Among the 35/72 CSNs and 110/115 CPNs with perimovement activity, several features emerged that emphasized the similarities and differences between the two efferent populations. Figures 8 and 9 illustrate some of the features that could be found in both cell types. Perimovement modulations often began at least $100 \mathrm{msec}$ before movement onset and were nearly always influenced by the direction of movement. For the examples in Figure 8, $A$ and $B$, and Figure $9 B$, a marked increase in firing preceded extension movements but little or no change was present for flexions. For the CSN activity illustrated in Figure $9 A$, perimovement firing was present only for flexion movements. In some cells, torque loads influenced the magnitude of the perimovement modulation (e.g., dynamic
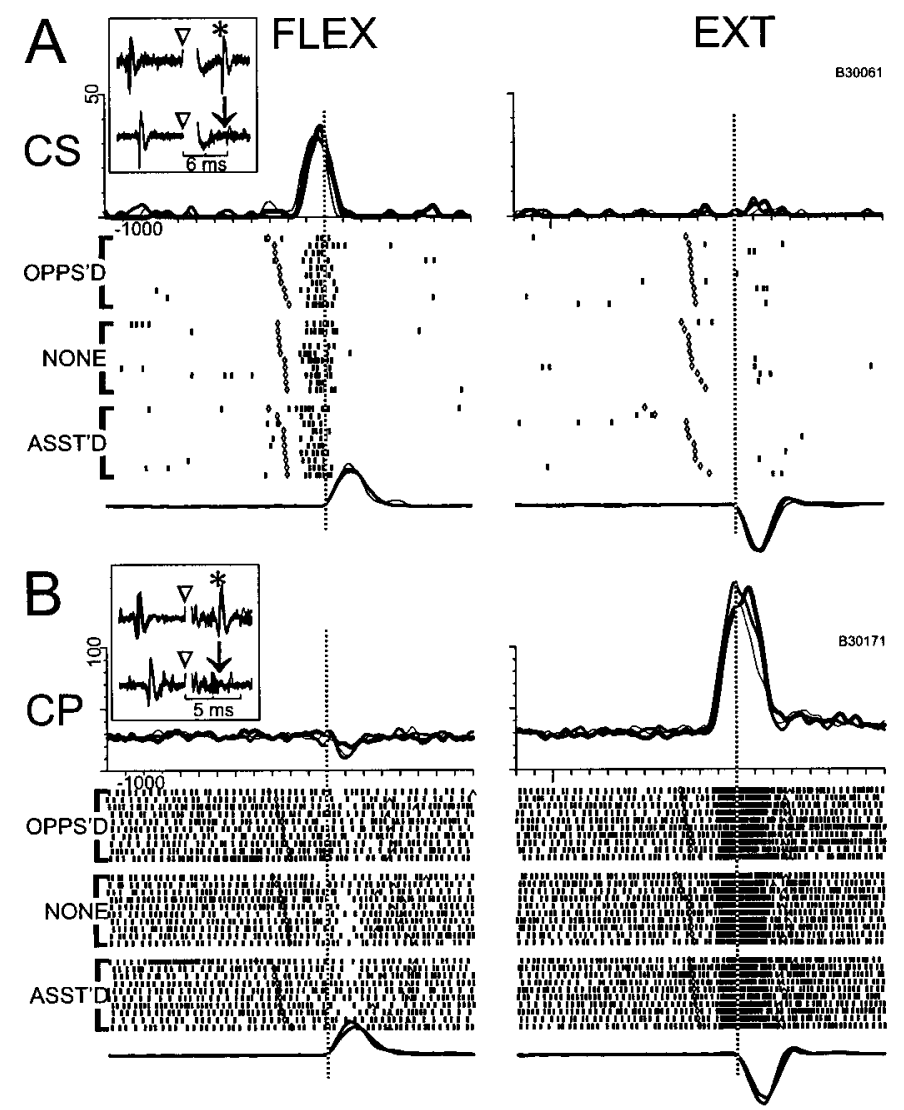

Figure 9. Representative examples of "directional" perimovement activity in $\mathrm{CS}$ and $\mathrm{CP}$ neurons ( $A$ and $B$, respectively). For both neurons, perimovement activity was strongly modulated by the direction of movement but was uninfluenced by opposing or assisting torque loads (OPPOS' $D$ and $A S S T$ 'D raster diagrams, respectively), and the mean SDFs had very similar profiles for the three loading conditions (opposed, no-load, and assisted conditions denoted, respectively, by thick, medium, and thin traces overlaid at top). Other conventions follow those of previous figures.

load effects) (Fig. 8A,B) and/or the cell's tonic firing rate during the preinstruction delay period (static load effects) (Fig. 8B). The pattern of dynamic and/or static load effects often mimicked what was seen in the EMG activity of agonist muscles, such that loads opposing and assisting movement in the cell's preferred direction caused the cell to have greater and smaller changes in firing, respectively (Fig. $8 A, B$ ). Note, for the cell activity illustrated in Figure $8 B$, the dynamic load effect had a muscle-like activation pattern, whereas the static load effect followed a non-muscle-like pattern (i.e., preinstruction activity was elevated when loads assisted movement into the cell's preferred direction). Various nonmuscle-like load effects were found for both cell types. Finally, for many cells, torque loads had no perceptible influence on perimovement phasic firing or on premovement tonic rates (Fig. 9A,B).

For both CSNs and CPNs, perimovement activity often began well before the onset of movement (Figs. 8, 9, 11B). As shown in Figure $10 B$, more than half of the CSNs $(57 \%, 20 / 35)$ had early movement-related activity that began within a $95 \%$ confidence range for the CPN latency distribution [65-195 msec before movement onset, calculated using a robust estimator for dispersion around the median (Rousseeuw, 1990)]. For the remaining 15/35 CSNs, movement-related activity began close to or after movement onset. The overall latency distributions for CS and CP populations differed significantly (medians $=-130 \mathrm{msec}$ vs $-70 \mathrm{msec}$, respectively; Komolgorov two-sample test, $p<0.005$ ). For comparison, the earliest agonist EMG activity observed in monkey L preceded movement by $135 \mathrm{msec}$ (earliest agonist = extensor carpi radialis; $n=15$ arm muscles, range $=-135 \mathrm{msec}$ to $-40 \mathrm{msec}$, median $=$ $-87 \mathrm{msec})$. 

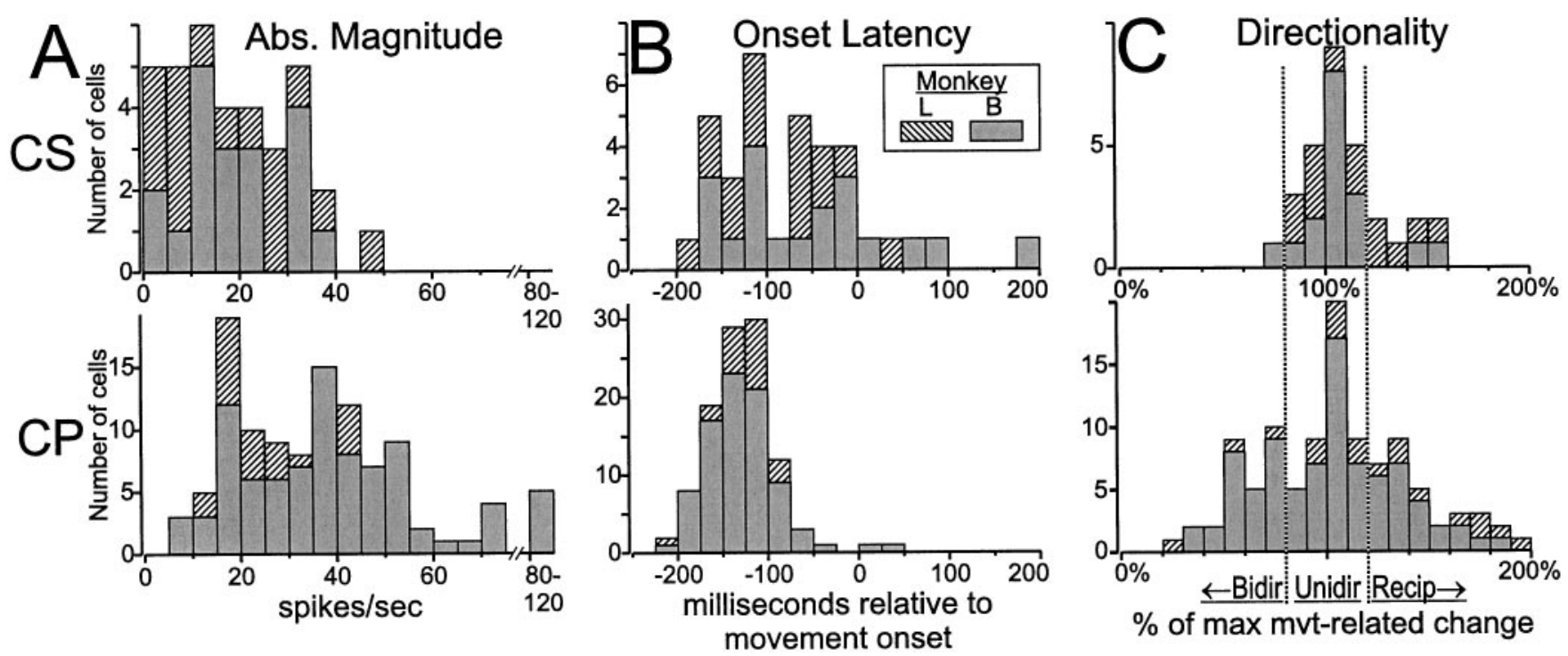

Figure 10. Contrasting properties of perimovement activity in CSNs and CPNs. Compared with CPNs, the perimovement activity of CSNs was as follows: $A$, smaller in magnitude, and $B$, later in onset relative to the start of movement. $C$, For CSNs, perimovement activity was most commonly present for only one direction of movement (Unidir, reflected by an IDM $\sim 100 \%$ ), whereas substantial numbers of CPNs had movement-related activity that was either of the same sign for both directions (Bidir, IDM $<80 \%$ ) or of opposite signs for the two directions (Recip, IDM > 120\%). IDM distributions are shown in histogram form for all neurons that had significant perimovement activity. Similar differences were observed for cells sampled from monkeys L and B (denoted by hatching and gray shading, respectively).

\begin{tabular}{|c|c|c|c|c|}
\hline & CS & $\mathrm{CP}$ & CP low-f & NA low-f \\
\hline \multicolumn{5}{|l|}{ Direction effects } \\
\hline Total task-related cells & 35 & 110 & 26 & 69 \\
\hline Significant direction effects & $31(89)$ & $106(96)$ & $24(92)$ & $66(96)$ \\
\hline \multicolumn{5}{|l|}{ Types of directionality } \\
\hline Unidirectional & $22(71)$ & $43(41)$ & $16(67)$ & $38(58)$ \\
\hline Reciprocal & $8(26)$ & $34(32)$ & $3(13)$ & $7(11)$ \\
\hline Bidirectional & $1(3)$ & $29(27)$ & $5(21)$ & $21(32)$ \\
\hline \multicolumn{5}{|l|}{ Dynamic load effects } \\
\hline Total task-related cells tested with loads & 34 & 108 & 26 & 67 \\
\hline Significant dynamic effects & $16(47)$ & $58(54)$ & $12(46)$ & $44(66)$ \\
\hline \multicolumn{5}{|l|}{ Static load effects } \\
\hline Total cells tested with loads & 66 & 112 & 26 & 74 \\
\hline Significant static effects & $16(24)$ & $51(46)$ & $7(27)$ & $29(39)$ \\
\hline
\end{tabular}

The number (and percentage) of neurons whose perimovement activity was influenced by movement direction (Direction effects) and torque loads (Dynamic load effects and Static load effects) tabulated for four categories of neurons: CS, corticostriatal neurons; CP, corticopeduncular neurons; CP low-f, corticopeduncular neurons that had spontaneous rates $<7.5$ spikes/sec; NA low-f, neurons that were not activated antidromically and had spontaneous rates $<7.5$ spikes/sec. The tabulated effects were judged significant if the ANOVA factor (direction or load) was significant in the main effect or any interaction term $(p<0.001)$. Types of directionality were determined by the magnitude of the IDM: $\geq 120 \%$, reciprocal; $<120 \%$ and $\geq 80 \%$, unidirectional; $<80 \%$, bidirectional. (For the derivation of IDMs, see Materials and Methods/Data analysis.)

\section{Movement direction}

For large proportions of CS and CP populations, perimovement activity was different for the two directions of movement (Table 1) $\left(\chi^{2}=3.1, p=0.08\right)$. The directional effects, however, tended to have different forms for the two cell populations. For CSNs, perimovement activity was most commonly present for only one movement direction (unidirectional in Table 1; see, e.g., Figs. $8 A, 9 A$, and $10 C$ ), whereas CPNs were more likely to have reciprocal (Figs. $7 B, 9 B$ ) or bidirectional forms (Fig. $8 B$ ). CSNs were 3.6 times more likely than CPNs to follow the unidirectional pattern $\left(\chi^{2}=11.3\right.$, $p<0.005)$. Because reciprocal directionality requires a decrease below the spontaneous rate for one movement direction, the low incidence of reciprocal directionality in CSNs was probably a direct consequence of their low spontaneous rates. Consistent with this explanation, reciprocal directionality was also rare in slowly firing $\mathrm{CP}$ and NA neurons (<7.5 spikes/sec; CP low-f and NA low-f in Table 1). The scarcity of bidirectional activity in CSNs, however, could not be attributed to low spontaneous firing rates. Bidirectional activity was 11.3 times less common in CSNs than in CPNs $\left(\chi^{2}=10.9, p<0.005\right)$, and this difference persisted when comparisons were made with slowly firing CPNs $\left(\chi^{2}=7.9, p<0.05\right)$ and NA neurons $\left(\chi^{2}=12.7, p<0.002\right)$.

The paucity of bidirectional activity in CSNs was confirmed with a method that avoided categorization of directionality into discrete types. Figure $10 C$ shows the distributions of IDMs (see Materials and Methods for derivation) that were used to categorize directionality. Direct comparisons of the IDM distributions for CSNs and CPNs found a substantial difference for IDMs between 0 and 
Table 2. Summary of direction/load interactions

\begin{tabular}{lllll} 
& CS & CP & CP low-f & NA low-f \\
\hline Cells tested & \multicolumn{1}{l}{31} & 104 & 24 & 64 \\
Directional & $12(39 \%)$ & $30(29 \%)$ & $11(46 \%)$ & $15(23 \%)$ \\
Muscle-like & $6(19 \%)$ & $40(38 \%)$ & $10(42 \%)$ & $29(45 \%)$ \\
Other & $13(42 \%)$ & $34(33 \%)$ & $3(13 \%)$ & $20(31 \%)$
\end{tabular}

The number (and percentage) of neurons in which movement direction and torque loads influenced perimovement activity according to one of the following patterns: Directional, significant direction effect with no load effects; Muscle-like, significant direction-by-load interaction in which loads opposing a cell's preferred direction of movement were correlated with elevated perimovement activity; Other, any significant load effect or direction-by-load interaction that did not fit the muscle-like pattern. Neuronal categories (CS, CP, CP low-f, and NA low-f) are explained in caption for Table 1 .

$100 \%$ (i.e., for activity patterns that could possibly be classified as bidirectional; $p<0.005$, Kolmogorov-Smirnov two-sample test) but no reliable difference between distributions for IDMs $>100 \%$ $(p=0.43)$. This is consistent with the view that CSN perimovement activity (as well as that related to somatosensory stimulation, as discussed above) has a directional sensitivity that is more focused or selective for specific directions of movement than is true for CPNs or a general population of M1 cells.

\section{Torque loads}

Effects of torque load on a cell's perimovement firing (i.e., dynamic load effects) were found in approximately half of the cells that had perimovement changes in activity, regardless of whether they were CSNs or CPNs (Table 1$)\left(\chi^{2}=0.4, p=0.49\right)$. The various forms that these effects took and their interactions with directional effects are discussed below.

Effects of static loads on a cell's tonic rate were far less common in CSNs than in CPNs. Further examination revealed that this difference could be explained by the low spontaneous rates of CSNs. To aid comparison with previous studies (Bauswein et al., 1989), all cells recorded during application of loads were tested for static load effects, regardless of whether the cell had a significant change in perimovement activity. Static load effects were approximately half as common in CSNs as in the general population of CPNs (Table 1) $\left(\chi^{2}=8.0, p<0.005\right)$. The other slowly firing cell populations had similar low incidences of static load effects (CS vs CP low-f; $\chi^{2}=0.1, p=0.69$; CS vs NA low-f; $\chi^{2}=4.1, p=0.04$ ).

\section{Direction/load interactions}

Previous studies of the effects of movement direction and static torque on neuronal activity have classified the interactions of the two factors into three mutually exclusive categories (Evarts, 1967; Conrad et al., 1977; Crutcher and DeLong, 1984; Crutcher and Alexander, 1990): (1) the directional pattern, in which perimovement activity codes the direction of movement independent of, and uninfluenced by, loading conditions (Fig. 10A,B); (2) the musclelike pattern, in which the pattern of perimovement activity resembles what would be seen in an agonist muscle (Fig. 9A,B); and (3) a collection of other, nonstandard interaction patterns (e.g., increased firing when loads assist movement into the cell's preferred direction; data not shown). Perimovement activity was categorized according to this scheme for all of the cells tested both with loads and with significant perimovement activity. As Table 2 shows, CPNs were 2.6 times more likely than CSNs to have a muscle-like pattern of activity $\left(\chi^{2}=6.0, p<0.05\right)$. The muscle-like pattern was similarly rare in CSNs when compared with its incidence in slowly firing subpopulations of CPNs (odds ratio $=1: 2.9$; too few cells for reliable statistics) and NA neurons (odds ratio $=1: 3.4 ; \chi^{2}=8.5$, $p<0.02)$.

\section{Preparatory activity}

Preparatory activity, defined as increased or decreased neuronal firing during a postinstruction interval, is thought to reflect the

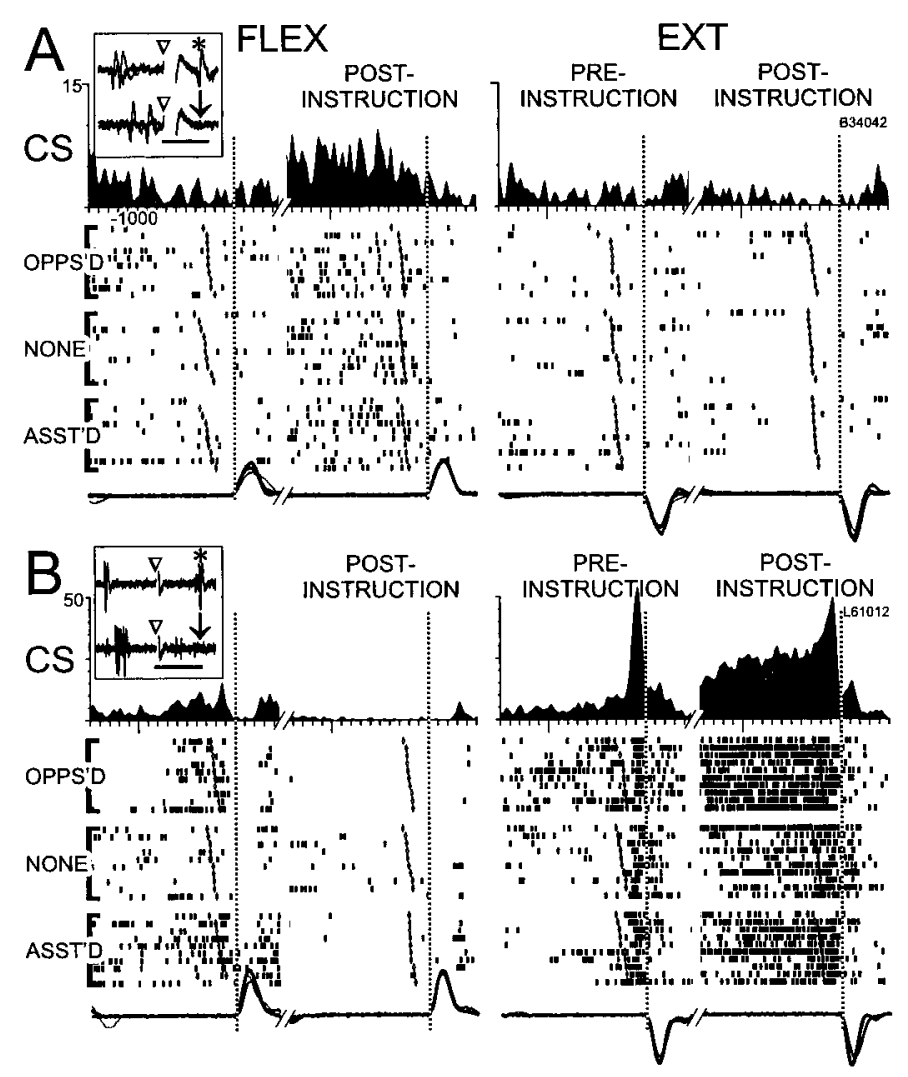

Figure 11. Examples of "preparatory alone" and "combined" categories of preparatory activity. A, Preparatory activity in the absence of perimovement firing, like that shown in this example, was more common in CSNs than in CPNs. Tonic firing during the postinstruction period was increased for flexion trials (left) but was absent for extension trials (right). There was no change in firing related to the first or second movement (left and right vertical dotted lines) for either flexion or extension trials. $B$, A combination of preparatory and movement-related activity was observed in CSNs, as illustrated here. $A$ and $B$ show two separate epochs of unit activity (SDFs and raster diagrams) and mean velocity traces for flexion (left) and extension (right) trials. The first epoch includes the preinstruction and first movement periods, whereas the second epoch includes postinstruction and second movement periods. The SDFs reflect mean firing rates across the three loading conditions, whereas separate raster diagrams and velocity traces (overlaid below) are shown for each loading condition. In other respects, the conventions of previous figures are followed. Time scales for inset figures: $A, 4 \mathrm{msec} ; B, 15 \mathrm{msec}$.

implementation and maintenance of pretrigger aspects of a motor plan (Evarts et al., 1984; Alexander and Crutcher, 1990). Two types of preparatory activity were observed in CSNs and CPNs. Shown in Figure $11 A$ is a representative example of preparatory activity in a CSN in the absence of perimovement activity (i.e., preparatory alone activity). The cell's firing was tonically elevated during the postinstruction period of flexion trials up to the presentation of the postinstruction trigger before the second movement (Fig. 11 A, left panel, second vertical dotted line $)(p<0.001$, epoch $\times$ direction interaction). The cell's tonic firing was slightly depressed during the postinstruction period of extension trials (Fig. 11A, right panel). Static loads did not influence this neuron's activity during preinstruction or postinstruction periods $(p>0.3)$. A conjunction of preparatory and movement-related activity was observed in other neurons, as illustrated for a CSN in Figure $11 B$. For this example, there was a sustained elevation in firing during the postinstruction period of extension trials (right panel; $p<0.001$, epoch $\times$ direction interaction) combined with a burst of activity that immediately preceded both first and second extension movements. During the postinstruction period of flexion trials, the neuron's firing was depressed below its spontaneous rate. For this neuron, flexing loads elevated the tonic firing rate, but the effects of load and preparation 
Table 3. Segregation of preparatory activity, perimovement activity, and sensory responses

\begin{tabular}{lcccc} 
& CS & CP & CP low-f & NA low-f \\
\hline Total cells & 70 & 114 & 27 & 70 \\
Prep alone & $4 / 12(33)$ & $1 / 50(2)$ & $1 / 9(11)$ & $0 / 17(0)$ \\
Mvt alone & $20 / 39(51)$ & $6 / 109(6)$ & $2 / 26(8)$ & $15 / 69(22)$ \\
Sensory alone & $13 / 27(48)$ & $4 / 101(4)$ & $0 / 22(0)$ & $4 / 56(7)$
\end{tabular}

The fraction (and percentage) of neurons that were activated exclusively during the preparatory period (Prep alone), during active movement (Mvt alone, for task performance and/or motor exam), or during sensory stimulation (Sensory alone, short latency torque responses and/or sensory exam). The denominator for each category equals the total number of neurons showing that category of activity (preparatory, movement-related, or sensory). Exclusive relations to each signal type were more common among CSNs than for any other cell category.
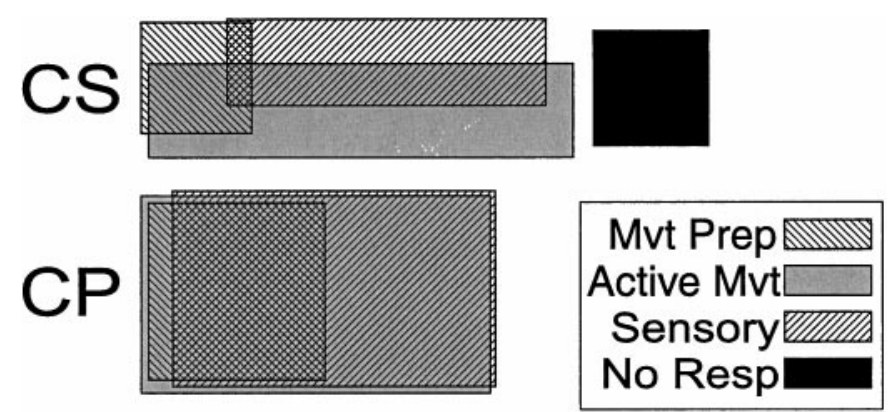

Figure 12. Ven diagrams of the combinations of three types of activity in CSNs and CPNs. CSNs were more likely than CPNs to respond exclusively to one of the three factors: preparation to move (Mvt Prep), active movement (Active $M v t$ ), or sensory stimulation (Sensory). A substantial fraction of CSNs $(19 \%)$ were unresponsive to all factors (No Resp), whereas all CPNs were activated by at least one factor.

were additive (i.e., no significant interaction between epoch and loading condition).

Preparatory activity was relatively rare among cells that fired at low spontaneous rates, regardless of whether they were CSNs, CPNs, or NA neurons. Preparatory activity was 2.5 times less common in CSNs than in the general population of CPNs (12/70 vs $\left.50 / 114 ; \chi^{2}=13.8, p<0.0002\right)$, but no reliable difference was found in the incidence of preparatory activity between CSNs and the slowly firing subpopulations of CP (6/21) or NA neurons $(14 / 60$; no significant differences in $\chi^{2}$ analyses). The preparatory activities of CSNs and CPNs were similar in other respects. They were affected by the direction of upcoming movement and by static torque loads at roughly equal rates, and no substantial differences were found in the incidences of different patterns of directionality (i.e., unidirectional, reciprocal, or bidirectional preparatory activity).

\section{Selective activation of CSNs}

Most CSNs $(81 \%, 57 / 70)$ were activated by at least one of the tasks or manipulations used. Many CSNs were activated exclusively during movement preparation, active movement, or sensory stimulation, whereas very few CPNs responded to one factor alone (Table 3, Fig. 12). Preparatory activity alone (Fig. 11A) was 24 times more common among CSNs than among CPNs (Table 3, Prep alone) $\left(\chi^{2}=12.8, p<0.001\right)$. Preparatory activity by itself was also more common for CSNs than for the slowly firing subpopulations of CPNs (odds ratio $=4: 1, \chi^{2}$ not significant) and NA neurons $\left(\chi^{2}=6.6, p<0.05\right)$. It is important to emphasize, however, that the greater segregation of preparatory activity in CSNs was relative to that found for other cell populations. More than half of the CSNs with preparatory activity $(58.3 \%, 7 / 12)$ also had movement-related activity (Fig. 11B).

Compared with CPNs, CSNs were also far more likely to fire exclusively during active movement (Table 3 , Mvt alone) $\left(\chi^{2}=\right.$
41.6, $p<0.001$ ) or during sensory stimulation (Table 3, Sensory alone) $\left(\chi^{2}=36.1, p<0.001\right)$. These two comparisons also did not depend on the low spontaneous rates of CSNs $\left(p<0.001\right.$ for all $\chi^{2}$ comparisons with slowly firing $\mathrm{CPN}$ and NA cells). Finally, a substantial minority of CSNs $(19 \%, 13 / 70)$ were not activated by any of the tasks or manipulations. In contrast, all CPNs responded to at least one aspect of the task, and only $5 \%$ (4/78) of the slowly firing NA neurons were unresponsive.

\section{DISCUSSION}

The present study indicates that the motor cortex exports distinctly different messages to the striatum and spinal cord/brainstem. Not only does the primate corticostriatal projection originate from a population of neurons separate from CPNs, but the functional properties of CSNs differ from those of other M1 neurons. Relative to nearby CPNs, CSNs had slower conduction velocities, lower spontaneous rates, lower incidences of sensory responsiveness and task-related activity, and greater directional selectivity in the somatosensory and movement-related activities. The perimovement activity of CSNs was of smaller magnitude, began later on average, and seldom showed a muscle-like pattern of load effects. Finally, unlike CPNs, many CSNs exclusively signaled movement preparation, active movement or sensory stimulation. These results are consistent with a previous study of CSNs in monkey M1 (Bauswein et al., 1989). The 21 CSNs of that study had slow conduction velocities, low spontaneous rates, and a paucity of task-related activity compared with nearby pyramidal tract neurons. The responsive CSNs were selective for either sensory stimulation (short latency torque responses) or active movement. The smaller number of CSNs sampled by Bauswein et al. (1989) precluded extensive statistical analysis, however, and the behavioral task was limited in scope. The present results extend those observations with a task that dissociates torque perturbation, loading direction, direction of movement, and movement preparation. Previous use of the same task (Crutcher and Alexander, 1990; Alexander and Crutcher, 1990) permits reliable comparison with results from the M1recipient striatum. Furthermore, the present study compares CSNs with a general class of corticofugal neuron and establishes statistical reliability with a larger number of CSNs sampled from two animals.

On two notable points, the present results differ from those of Bauswein et al. (1989). First, a larger proportion of CSNs studied here $(81 \%$ vs their $\sim 50 \%)$ were activated by at least one behavioral factor. The increased responsiveness probably stems from the more complex behavioral task and the use of sensorimotor examination. From our observations we would characterize CSNs as difficult to activate because they are selective for specific movements, stimuli, or contexts, and not because they are intrinsically "unresponsive." A second notable finding was that CSN movement-related activity often begins well in advance of movement initiation, whereas Bauswein et al. (1989) reported that CSN onsets typically followed movement onset. The latency difference is likely attributable to differences in tasks, the most conspicuous being that we studied visually triggered movement whereas the movements Bauswein et al. (1989) studied were compensatory responses to torque perturbations.

Two recent studies in cats found only minor differences between CSNs and corticotectal neurons (Niida et al., 1997; Weyand and Gafka, 1998), and those differences indicated that CSNs were less selective for specific visual stimuli than neighboring corticotectal cells. The disparity with the present results may be explained by the different cortical areas sampled and accompanying differences in CSN type (Gerfen and Wilson, 1996) and/or species differences. Available data, however, indicate that CSNs in multiple precentral areas of the primate [periarcuate premotor area (Bauswein et al., 1989) and supplementary motor area (R. S. Turner and M. R. DeLong, unpublished observations)] have characteristics similar to those reported here. 


\section{Segregation of signals among M1 efferent pathways}

The present results indicate that distinct signals are transmitted from M1 to the striatum and spinal cord/brainstem. Although consistent with some electrophysiological (Bauswein et al., 1989) and anatomical work (Hedreen, 1977; Jones et al., 1977), studies in nonprimate species have demonstrated striatal collaterals from corticospinal/pontine neurons (Donoghue and Kitai, 1981; Fisher et al., 1986; Cowan and Wilson, 1994; Serizawa et al., 1994; Levesque et al., 1996; Paré and Smith, 1996). Those studies describe two general types of CSNs: fast-conducting layer Vb neurons that innervate distant targets, and slowly conducting neurons the axon collaterals of which are restricted to telencephalic targets. The bulk of the CS projection in rodents consists of the slowly conducting type (Wilson et al., 1982; Levesque et al., 1996). We infer from the present results that in primate M1 the CS projection is also dominated by intra-telencephalic CSNs, and fast-conducting distant-projecting neurons rarely collateralize to striatum. The late timing of striatal activity evoked by M1 stimulation is consistent with this interpretation (Liles, 1974, 1975; Kocsis et al., 1977).

It is quite possible that a general class of intra-telencephalic M1 efferents have firing properties similar to what we found for CSNs. It has been known for some time that neurons located outside of layer $\mathrm{Vb}$ tend to differ from layer $\mathrm{Vb}$ cells in their task-related activities (Cheney and Fetz, 1980; Kalaska et al., 1989). The firing properties reported for non- $\mathrm{Vb}$ neurons approximate those found here for CSNs (i.e., low spontaneous rates and directional movement-related firing that is not influenced by loads). CSN-like properties have also been reported for slowly conducting corticocortical and callosal-projecting neurons in M1 of the rabbit (Swadlow, 1994). Furthermore, CSNs and corticocortical neurons have similar laminar distributions (Arikuni and Kubota, 1986), and slowly conducting CSNs often collateralize to ipsilateral and contralateral cortex (Wilson, 1987; Levesque et al., 1996).

The distinct firing properties of CSNs and CPNs likely arise from differences in both synaptic connectivity and intrinsic properties. For instance, slowly conducting CSNs receive few thalamocortical synapses (Kitai et al., 1976; Jinnai and Matsuda, 1979; Hersch and White, 1982), and their intrinsic ionic conductances differ from those of other corticof ugal types (Stewart and Foehring, 2000). Low spontaneous rates and a paucity of long-lasting activities (i.e., of static load effects and preparatory activity) may both result from the inwardly rectifying currents described for CSNs (Cowan and Wilson, 1994) and other cortical neurons (Yang et al., 1996). Such currents limit the duration of juxta-threshold "up" states and thereby restrict a neuron's ability to produce high tonic firing.

The present results, along with previous comparisons of M1 efferent systems (Fromm, 1983; Bauswein et al., 1989; Kably and Drew, 1998), caution against equating the functions of M1 with those of one corticofugal population. The difficulty of establishing good action potential isolation for CSNs suggests that few CSNs have been included in most chronic recording studies of M1. Unless a study is guided by selection criteria such as antidromic activation, sampling biases instead cause a marked oversampling of largespiking layer Vb cells [i.e., CPNs (Towe and Harding, 1970)]. We have shown, using antidromic activation, that M1 performs dual functions in parallel by communicating distinct aspects of a task to the striatum and spinal cord/brainstem.

\section{Corticostriatal signaling and basal ganglia functions}

Wilson and coworkers have argued that activation of a medium spiny neuron (MSN; the principal neuronal type of the striatum) requires synchronous excitation from many converging CSNs (Wilson, 1995; Stern et al., 1997). That result, combined with the low spontaneous rates and selective activity of CSNs observed here, predicts that few MSNs will be active under any one condition. The incidence of task-related activity among MSNs may indeed be lower than indicated by most extracellular recording studies, because the many silent MSNs (Kiyatkin and Rebec, 1999) are seldom detected. Additionally, thalamostriatal inputs [perhaps syn- chronized via thalamus-projecting CSNs (Paré and Smith, 1996)] may contribute substantially to the excitation of MSNs.

Opinions differ on what may be represented in the activity of CSNs. A commonly held view is that CSNs are "internal command collaterals" (McCloskey, 1981) that carry a replica of the signals a cortical column transmits to other targets [e.g., spinal cord (Houk, 1995; Redgrave et al., 1999)]. CSNs do not conform to the traditional definition of command collaterals, however, because their task-related activities differ substantially from those of CPNs. Bauswein et al. (1989) noted that CSN firing instead resembles that in M1-recipient areas of striatum [i.e., low spontaneous rates, directional perimovement activity with late onsets (Crutcher and DeLong, 1984), and infrequent load effects (Liles, 1985)]. The present results expand the list of $\mathrm{CSN} /$ striatal similarities to include a scarcity of muscle-like activity (Crutcher and Alexander, 1990) and frequent exclusive relations to preparation, movement, or sensory modalities (Liles, 1985; Alexander and Crutcher, 1990; Schultz et al., 1995). The early onsets that we found for CSN movementrelated activity (median $-70 \mathrm{msec}$ ), relative to those reported for MSNs [13 msec (Crutcher and Alexander, 1990)], can be attributed largely to differences in detection algorithms and task performance [i.e., earliest EMG activity here started $53 \mathrm{msec}$ before that reported by Crutcher and Alexander (1990)]. The resemblance between CSN and striatal activity suggests that many striatal firing properties are transferred from cortex rather than synthesized from synaptic interactions within the striatum. It is reasonable to expect, however, that some signals are not represented in the activity of CSNs, but emerge de novo from intrastriatal processing. For M1recipient striatum, those signals might include context dependence (Kimura, 1990; Kimura et al., 1992), sequence specificity (Ueda and Kimura, 1997), or reward contingency (Kawagoe et al., 1998).

Theorists view the corticostriatal system as an ideal substrate for the recognition of cortical states (Houk, 1995; Houk and Wise, 1995; Graybiel, 1998; Redgrave et al., 1999). The selectivity of CSN activity described here suggests that a "sparse code" is used to communicate cortical states to the striatum. The defining characteristic of sparse coding in a neuronal population is that each neuron responds to a small number or range of stimuli (Rolls and Tovee, 1995; Vinje and Gallant, 2000). Modeling studies have shown that sparse coding affords advantages over other coding schemes for the efficient, robust, and flexible representation of information (Földiák and Young, 1995). A low level of redundancy between neurons (i.e., infrequent correlated firing) is an attendant property of sparse coding that also appears at striatal (Jaeger et al., 1995; Kincaid et al., 1998) and pallidal (Nini et al., 1995) levels. Thus, a high degree of selectivity (i.e., sparse coding) may be an aspect of CSN signaling that is important for subsequent intra-BG processing.

\section{REFERENCES}

Alexander GE (1987) Selective neuronal discharge in monkey putamen reflects intended direction of planned limb movements. Exp Brain Res 67:623-634.

Alexander GE, Crutcher MD (1990) Preparation for movement: neural representations of intended direction in three motor areas of the monkey. J Neurophysiol 64:133-150.

Alexander GE, DeLong MR (1985) Microstimulation of the primate neostriatum. II. Somatotopic organization of striatal microexcitable zones and their relation to neuronal response properties. J Neurophysiol 53:1417-1430.

Arikuni T, Kubota K (1986) The organization of prefrontocaudate projections and their laminar origin in the macaque monkey: a retrograde study using HRP-Gel. J Comp Neurol 244:492-510.

Bauswein E, Fromm C, Preuss A (1989) Corticostriatal cells in comparison with pyramidal tract neurons: contrasting properties in the behaving monkey. Brain Res 493:198-203.

Brodal P (1978) The corticopontine projection in the rhesus monkey. Origin and principles of organization. Brain 101:251-283.

Calabresi P, Pisani A, Mercuri NB, Bernardi G (1996) The corticostriatal projection: from synaptic plasticity to dysfunctions of the basal ganglia. Trends Neurosci 19:19-24.

Cheney PD, Fetz EE (1980) Functional classes of primate corticomotoneuronal cells and their relation to active force. $\mathrm{J}$ Neurophysiol 44:773-791. 
Clower WT, Alexander GE (1998) Movement sequence-related activity reflecting numerical order of components in supplementary and presupplementary motor areas. J Neurophysiol 80:1562-1566.

Conrad B, Wiesendanger M, Matsunami K, Brooks VB (1977) Precentral unit activity related to control of arm movements. Exp Brain Res 29:85-95.

Cowan RL, Wilson CJ (1994) Spontaneous firing patterns and axonal projections of single corticostriatal neurons in the rat medial agranular cortex. J Neurophysiol 71:17-32.

Crutcher MD, Alexander GE (1990) Movement-related neuronal activity selectively coding either direction or muscle pattern in three motor areas of the monkey. J Neurophysiol 64:151-163.

Crutcher MD, DeLong MR (1984) Single cell studies of the primate putamen. II. Relations to direction of movement and pattern of muscular activity. Exp Brain Res 53:244-258.

Delfs JM, Ciaramitaro VM, Parry TJ, Chesselet MF (1995) Subthalamic nucleus lesions: widespread effects on changes in gene expression in duced by nigrostriatal dopamine depletion in rats. J Neurosci 15:6562-6575.

Donoghue JP, Kitai ST (1981) A collateral pathway to the neostriatum from corticofugal neurons of the rat sensory-motor cortex: an intracellular HRP study. J Comp Neurol 201:1-13.

Evarts EV (1967) Representation of movements and muscles by pyramidal tract neurons of the precentral motor cortex. In: Neurophysiological basis of normal and abnormal motor activities (Yahr MD, Purpura DP, eds), pp 215-253. New York: Raven.

Evarts EV (1973) Motor cortex reflexes associated with learned movement. Science 179:501-503.

Evarts EV, Shinoda Y, Wise SP (1984) Neurophysiological approaches to higher brain functions. New York: Wiley.

Fisher RS, Boylan MK, Hull CD, Buchwald NA, Levine MS (1986) Branched projections of cat sensorimotor cortex: multiple retrograde labeling via commissural corticocortical, decussated corticostriatal and undecussated corticostriatal axons. Brain Res 384:395-400.

Flaherty AW, Graybiel AM (1991) Corticostriatal transformations in the primate somatosensory system. Projections from physiologically mapped body-part representations. J Neurophysiol 66:1249-1263.

Földiák P, Young MP (1995) Sparse coding in the primate cortex. In: The handbook of brain theory and neural networks (Arbib MA, ed), pp 895-898. Cambridge, MA: MIT.

Fromm C (1983) Contrasting properties of pyramidal tract neurons located in the precentral or postcentral areas and of corticorubral neurons in the behaving monkey. In: Motor control mechanisms in health and disease (Desmedt JE, ed), pp 329-345. New York: Raven.

Fuller JH, Schlag JD (1976) Determination of antidromic excitation by the collision test: problems of interpretation. Brain Res 112:283-298.

Gerfen CR, Wilson CJ (1996) The basal ganglia. In: Handbook of chemical neuroanatomy (Swanson LW, Björklund A, Hökfelt T, eds), pp 371-468. New York: Elsevier.

Graybiel AM (1998) The basal ganglia and chunking of action repertoires. Neurobiol Learn Mem 70:119-136.

Hedreen JC (1977) Corticostriatal cells identified by the peroxidase method. Neurosci Lett 4:1-7.

Hersch SM, White EL (1982) A quantitative study of the thalamocortical and other synapses in layer IV of pyramidal cells projecting from mouse SmI cortex to the caudate-putamen nucleus. J Comp Neurol 211:217-225.

Houk JC (1995) Information processing in modular circuits linking basa ganglia and cerebral cortex. In: Models of information processing in the basal ganglia (Houk JC, Davis JL, Beiser DG, eds), pp 3-10. Cambridge, MA: MIT.

Houk JC, Wise SP (1995) Distributed modular architectures linking basal ganglia, cerebellum, and cerebral cortex: their role in planning and controlling action. Cereb Cortex 2:95-110.

Humphrey DR, Corrie WS (1978) Properties of pyramidal tract neuron system within a functionally defined subregion of primate motor cortex. J Neurophysiol 41:216-243.

Jaeger D, Gilman S, Aldridge JW (1990) A multiwire microelectrode for single unit recording in deep brain structures. J Neurosci Methods 32:143-148.

Jaeger D, Gilman S, Aldridge JW (1995) Neuronal activity in the striatum and pallidum of primates related to the execution of externally cued reaching movements. Brain Res 694:111-127.

Jinnai K, Matsuda Y (1979) Neurons of the motor cortex projecting commonly on the caudate nucleus and the lower brain stem in the cat. Neurosci Lett 13:121-126.

Jones EG, Coulter JD, Burton H, Porter R (1977) Cells of origin and terminal distribution of corticostriatal fibers arising in the sensory-motor cortex of monkeys. J Comp Neurol 173:53-80.

Kably B, Drew T (1998) Corticoreticular pathways in the cat. II. Discharge activity of neurons in area 4 during voluntary gait modifications. J Neurophysiol 80:406-424.

Kakei S, Hoffman DS, Strick PL (1999) Muscle and movement representations in the primary motor cortex. Science 285:2136-2139.

Kalaska JF, Cohen DAD, Hyde ML, Prud'homme M (1989) A comparison of movement direction-related versus load direction-related activity in primate motor cortex, using a two-dimensional reaching task. $\mathrm{J}$ Neurosci 9:2080-2102.
Kawagoe R, Takikawa Y, Hikosaka O (1998) Expectation of reward modulates cognitive signals in the basal ganglia. Nat Neurosci 1:411-416.

Kimura M (1990) Behaviorally contingent property of movement-related activity of the primate putamen. J Neurophysiol 63:1277-1296.

Kimura M, Aosaki T, Hu Y, Ishida A, Watanabe K (1992) Activity of primate putamen neurons is selective to the mode of voluntary movement: visually guided, self-initiated or memory-guided. Exp Brain Res 89:473-477.

Kincaid AE, Zheng T, Wilson CJ (1998) Connectivity and convergence of single corticostriatal axons. J Neurosci 18:4722-4731.

Kitai ST, Kocsis JD, Wood J (1976) Origin and characteristics of the cortico-caudate afferents: an anatomical and electrophysiological study. Brain Res 118:137-141.

Kiyatkin EA, Rebec GV (1999) Modulation of striatal neuronal activity by glutamate and GABA: iontophoresis in awake, unrestrained rats. Brain Res 822:88-106.

Kocsis JD, Sugimori M, Kitai ST (1977) Convergence of excitatory synaptic inputs to caudate spiny neurons. Brain Res 124:403-413.

Levesque M, Charara A, Gagnon S, Parent A, Deschenes M (1996) Corticostriatal projections from layer $\mathrm{V}$ cells in rat are collaterals of longrange corticofugal axons. Brain Res 709:311-315.

Liles SL (1974) Single-unit responses of caudate neurons to stimulation of frontal cortex, substantia nigra, and entopeduncular nucleus in cats. J Neurophysiol 37:254-265.

Liles SL (1975) Cortico-striatal evoked potentials in the monkey (macaca mulatta). Electroencephalogr Clin Neurophysiol 38:121-129.

Liles SL (1985) Activity of neurons in putamen during active and passive movements of wrist. J Neurophysiol 53:217-236.

McCloskey DI (1981) Corollary discharges: motor commands and perception. In: Handbook of physiology, section 1. The nervous system, Vol II. Motor control, part 2 (Brookhart JM, Mountcastle VB, Brooks VB, Geiger SR, eds), pp 1415-1448. Bethesda, MD: American Physiological Society.

Mitchell SJ, Richardson RT, Baker FH, DeLong MR (1987) The primate globus pallidus: neuronal activity related to direction of movement. Exp Brain Res 68:491-505.

Niida T, Stein BE, McHaffie JG (1997) Response properties of corticotectal and corticostriatal neurons in the posterior lateral suprasylvian cortex of the cat. J Neurosci 17:8550-8565.

Nini A, Feingold A, Slovin H, Bergman H (1995) Neurons in the globus pallidus do not show correlated activity in the normal monkey, but phase-locked oscillations appear in the MPTP model of Parkinsonism. J Neurophysiol 74:1800-1805.

Paré D, Smith Y (1996) Thalamic collaterals of corticostriatal axons: their termination field and synaptic targets in cats. J Comp Neurol 372:551-567.

Porter RH, Greene JG, Higgins Jr DS, Greenamyre JT (1994) Polysynaptic regulation of glutamate receptors and mitochondrial enzyme activities in the basal ganglia of rats with unilateral dopamine depletion. J Neurosci 14:7192-7199.

Redgrave P, Prescott TJ, Gurney K (1999) The basal ganglia: a vertebrate solution to the selection problem? Neuroscience 89:1009-1023.

Rolls ET, Tovee MJ (1995) Sparseness of the neuronal representation of stimuli in the primate temporal visual cortex. J Neurophysiol 73:713-726.

Rousseeuw PJ (1990) Robust estimation and identifying outliers. In: Handbook of statistical methods for engineers and scientists (Wadsworth HM, ed), pp 16.1-16.24. New York: McGraw-Hill.

Schultz W, Apicella P, Romo R, Scarnati E (1995) Context-dependent activity in primate striatum reflecting past and future behavioral events. In: Models of information processing in the basal ganglia (Houk JC, Davis JL, Beiser DG, eds), pp 11-27. Cambridge, MA: MIT.

Serizawa M, McHaffie JG, Hoshino K, Norita M (1994) Corticostriatal and corticotectal projections from visual cortical areas 17, 18 and 18a in the pigmented rat. Arch Histol Cytol 57:493-507.

Stern EA, Kincaid AE, Wilson CJ (1997) Spontaneous subthreshold membrane potential fluctuations and action potential variability of rat corticostriatal and striatal neurons in vivo. J Neurophysiol 77:1697-1715.

Stewart A, Foehring RC (2000) Calcium currents in retrogradely labeled pyramidal cells from rat sensorimotor cortex. J Neurophysiol 83:2349-2354.

Swadlow HA (1994) Efferent neurons and suspected interneurons in motor cortex of the awake rabbit: axonal properties, sensory receptive fields, and subthreshold synaptic inputs. J Neurophysiol 71:437-453.

Szucs A (1998) Applications of the spike density function in analysis of neuronal firing patterns. J Neurosci Methods 81:159-167.

Takada M, Tokuno H, Nambu A, Inase M (1998) Corticostriatal projections from the somatic motor areas of the frontal cortex in the macaque monkey: segregation versus overlap of input zones from the primary motor cortex, the supplementary motor area, and the premotor cortex. Exp Brain Res 120:114-128.

Towe AL, Harding GW (1970) Extracellular microelectrode sampling bias. Exp Neurol 29:366-381.

Turner RS, Anderson ME (1997) Pallidal discharge related to the kinematics of reaching movements in two dimensions. J Neurophysiol 77:1051-1074.

Turner RS, DeLong MR (1993) A comparison of task-related discharge in corticostriatal and corticobulbar/spinal neurons in primary motor cortex Soc Neurosci Abstr 19:779. 
Turner RS, DeLong MR (1999) Corticostriatal (CS) task-related discharge in monkey M1 is similar to striatal discharge patterns. Soc Neurosci Abstr 29:779.

Ueda Y, Kimura M (1997) Contrasting properties of activity of primate putamen and primary motor cortex neurons during sequential motor behavior. Soc Neurosci Abstr 23:465.

Vinje WE, Gallant JL (2000) Sparse coding and decorrelation in primary visual cortex during natural vision. Science 287:1273-1276.

Weinrich M, Wise SP (1982) The premotor cortex of the monkey. J Neurosci $2: 1329-1345$.

Weyand TG, Gafka AC (1998) Corticostriatal and corticotectal neurons in area 6 of the cat during fixation and eye movements. Vis Neurosci 15:141-151.
Wilson CJ (1987) Morphology and synaptic connections of crossed corticostriatal neurons in the rat. J Comp Neurol 263:567-580.

Wilson CJ (1995) The contribution of cortical neurons to the firing pattern of striatal spiny neurons. In: Models of information processing in the basal ganglia, (Davis JL, Beiser DB, eds), pp 29-50. Cambridge, MA: MIT.

Wilson CJ, Chang HT, Kitai ST (1982) Origins of postsynaptic potentials evoked in identified rat neostriatal neurons by stimulation in substantia nigra. Exp Brain Res 45:157-167.

Winters WD, Kado RT, Adey WR (1969) A stereotaxic brain atlas for Macaca nemestrina. Berkeley, CA: University of California.

Yang CR, Seamans JK, Gorelova N (1996) Electrophysiological and morphological properties of layers V-VI principal pyramidal cells in rat prefrontal cortex in vitro. J Neurosci 16:1904-1921. 